UNIVERSIDADE DE SÃO PAULO

ESCOLA DE ENFERMAGEM

DORIS ELISABETH AMMANN SAAD

AUTONOMIA PROFISSIONAL DA ENFERMEIRA OBSTÉTRICA

São Paulo

2008 


\section{AUTONOMIA PROFISSIONAL DA ENFERMEIRA OBSTÉTRICA}

Dissertação apresentada ao Programa de Pós-Graduação em Enfermagem, Curso de Mestrado, Área Enfermagem Obstétrica e Neonatal, da Escola de Enfermagem da Universidade de São Paulo para obtenção do grau de Mestre em Enfermagem.

Orientadora:

Prof $^{\mathrm{a}}$. Dr ${ }^{\mathrm{a}}$. Maria Luiza Gonzalez Riesco

São Paulo

2008 


\section{Catalogação na Publicação (CIP) \\ Biblioteca "Wanda de Aguiar Horta" \\ Escola de Enfermagem da Universidade de São Paulo}

Saad, Doris Elisabeth Ammann

Autonomia profissional da enfermeira obstétrica. / Doris

Elisabeth Ammann Saad. - São Paulo, 2008.

$79 \mathrm{p}$.

Dissertação (Mestrado) - Escola de Enfermagem da Universidade de São Paulo.

Orientadora: Prof ${ }^{\mathrm{a}}$ Dra $^{\mathrm{a}}$ Maria Luiza Gonzalez Riesco

1. Enfermagem obstétrica 2. Enfermeiras obstétricas 3. Parto (assistência; enfermagem) I. Título 


\section{DEDICATÓRIA}

Às minhas filhas Mariana, Laura e Isabel. 


\section{AGRADECIMENTOS}

Agradeço à minha família que com carinho e paciência sempre me ajudou nas horas difíceis dando-me força e coragem para continuar.

A Maria Luiza Gonzalez Riesco que é a responsável pela minha volta à Escola de Enfermagem da Universidade de São Paulo, depois de tantos anos e que de maneira tranqüila, constante, dedicada e carinhosa me conduziu por este caminho do estudo para a realização deste trabalho.

Aos meus queridos amigos Daniel, Cecília, Ramiro, Maricy, Érica, Ana, Josy, Rose, D. Maria, do Grupo de Apoio a Maternidade e Paternidade (GAMP), que me apoiaram ao longo de todo o processo deste trabalho.

Agradeço a todas as Enfermeiras Obstétricas que me acompanharam e participaram diretamente ou indiretamente do projeto.

A Patrícia Logullo e Paulina Santa Cruz que me deram coragem e calma para terminar o trabalho.

A todos os meus amigos que de perto apostaram e me incentivaram de forma carinhosa, a alcançar mais este objetivo em minha vida. 
Saad DEA. Autonomia profissional da enfermeira obstétrica. [dissertação] São Paulo: Escola de Enfermagem da Universidade de São Paulo; 2008.

\section{RESUMO}

O modelo de assistência ao parto o Brasil está fortemente relacionado à atuação do médico e a maioria dos partos é realizada em ambiente hospitalar: em 2004, 94\% dos partos foram hospitalares e $43 \%$ dos nascimentos ocorreram por cesariana, uma atividade estritamente médica. Na rede privada de serviços de saúde do município de São Paulo, o percentual de cesarianas gira em torno de $84 \%$. A partir do final da década de 1990, vêm sendo formuladas políticas públicas para promover mudanças nesse modelo. Algumas dessas proposições favorecem a inserção de enfermeiras obstétricas e obstetrizes (EO) na assistência ao parto, reconhecendo sua importância para promover o parto normal. Nesse contexto, a autonomia profissional da EO na atenção de baixo risco e o trabalho colaborativo na assistência ao parto são elementos fundamentais para uma atenção qualificada. Por sua vez, a atuação da EO na assistência ao parto é definida não exclusivamente pelas políticas de saúde oficiais, mas também pela organização da assistência praticada nas instituições. A forma como a EO atua na assistência ao parto e como vivencia a autonomia profissional e o trabalho colaborativo dependem do local de atuação, das regras e normas da instituição, da divisão técnica do trabalho e da relação hierárquica estabelecida na equipe obstétrica. O objetivo deste estudo foi descrever como a enfermeira obstétrica percebe sua inserção na equipe obstétrica e sua autonomia profissional na assistência à mulher durante o parto, em instituições de saúde privadas. Foi utilizada a metodologia qualitativa e o estudo foi realizado com EO que atuavam em instituições de saúde privadas da cidade de São Paulo, que atendem exclusivamente pacientes particulares ou usuários de seguros ou planos de saúde. Os dados foram coletados por meio de entrevista semi-estruturada, como uso do gravador. Foram incluídas 15 EO que atuavam no centro obstétrico de nove instituições de saúde privadas. A análise de conteúdo foi utilizada para sistematizar os dados qualitativos e a discussão foi realizada considerando os seguintes temas: Autonomia; Confiança e cumplicidade: principais facilitadores da autonomia; Outros aspectos facilitadores da autonomia; Dificuldades para a autonomia; Facilitadores do trabalho colaborativo; Barreiras para o trabalho colaborativo; Percepção da inserção da enfermeira obstétrica na equipe; Composição e coordenação da equipe de assistência ao parto; Reflexões sobre a atuação da enfermeira obstétrica nas instituições de saúde privadas. Identificamos que apesar do apoio legal e do reconhecimento dos órgãos oficiais e organizações internacionais da importância da EO assistência à mulher no parto, sua atuação nas instituições privadas do município de São Paulo é muito restrita e aquém das competências estabelecidas para esta profissional. As EO apontaram o não reconhecimento de suas atribuições pelos médicos obstetras como um dos principais fatores para a restrição de sua autonomia e para a falta de trabalho colaborativo no cuidado da parturiente.

PALAVRAS-CHAVE: Enfermeiras obstétricas. Autonomia profissional. Comportamento cooperativo. Setor privado. 
Saad DEA. Professional autonomy of the nurse-midwife. [Master's degree dissertation] São Paulo: Escola de Enfermagem da Universidade de São Paulo; 2008.

\begin{abstract}
The model of healthcare during labor in Brazil is strongly associated to the physician care, and the majority of deliveries occur in hospitals: in 2004, $94 \%$ of the deliveries took place in hospitals and $43 \%$ of them were cesarian sections, something that implies medical care. In the private health system in the city of São Paulo, the incidence of cesarian section deliveries reaches around $84 \%$. Since the end of the 1990-decade, some political initiatives have been trying to change this model. Some of the proposals favor the insertion of nurse-midwives in the assistance team, recognizing the importance of this professional in the promotion of normal delivery. In that context, the professional autonomy of the nurse-midwife and collaborative work in the delivery assistance are essential for a qualified care. However, the role of the nurse-midwife in the delivery assistance is defined not only by official guidelines, but also by the institutions' policies. The way she can live professional autonomy and collaborative work depends on the type of hospital, its rules and norms, on the distribution of work among the team's members and on the hierarchical relationships. This study had the objective of describing the nursemidwife's perception of her insertion in the assistance team and of her professional autonomy in private hospitals. This was a qualitative study, with nurse-midwives working in private institutions in São Paulo that assist members of health care insurance plans. Data were collected by means of semi-structured interviews, registered in a tape recorder, with 15 nurse-midwives who work in 9 private hospitals. Content analysis was used and the qualitative data collected was discussed based on the themes: autonomy, factors that facilitate autonomy or factors that make autonomy more difficult, facilitators of collaborative work and factors that make it more difficult, the composition and coordination of the delivery health care team and the perception of the nurse-midwife of her insertion in the team. We observed that, despite the legal support and the recognition of official and international organizations about the role of the nurse-midwife, her actual work in the private hospitals in São Paulo is restricted and are not in accordance with her competence and skills. The nurse-midwives pointed out that obstetricians do not recognize their responsibilities in the health care team, and this restricts her autonomy and plays against the collaborative work in the patient's benefit.
\end{abstract}

KEYWORDS: Nurse midwives. Professional autonomy. Cooperative behavior. Private sector. 


\section{LISTA DE FIGURAS}

Figura 1. Fluxograma da seleção das instituições do estudo.

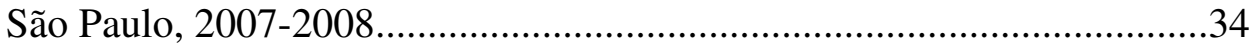




\section{LISTA DE QUADROS}

Quadro 1. Número da EO entrevistada e código da instituição de saúde.

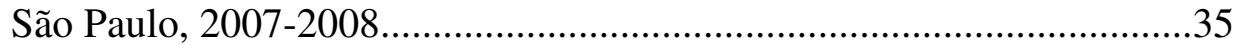

Quadro 2. Caracterização das EO entrevistadas. São Paulo, 2007-2008...................39 


\section{Sumário}

1 INTRODUÇÃO.

1.1 Atuação e formação profissional das parteiras, obstetrizes

e enfermeiras obstétricas.

1.2 A formação da obstetriz ou enfermeira obstétrica na atualidade .........................16

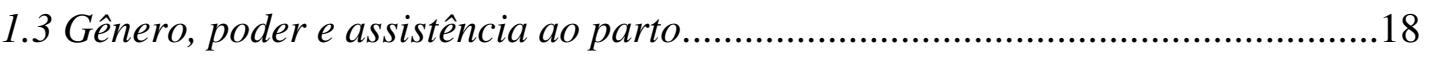

1.4 Assistência ao parto no Brasil............................................................................20

1.4.1 A rede privada de assistência ao parto - Sistema de Saúde

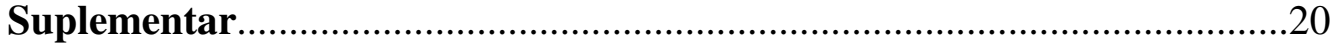

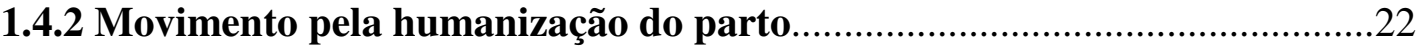

1.5 Autonomia profissional e o trabalho colaborativo da enfermeira

obstétrica na assistência ao parto.....................................................................24

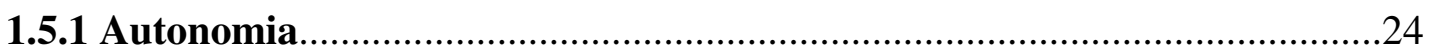

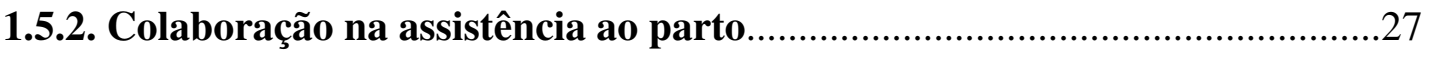

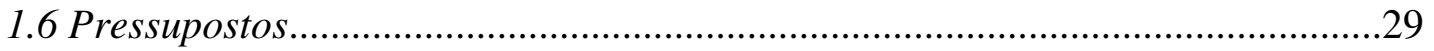

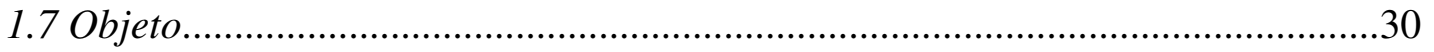

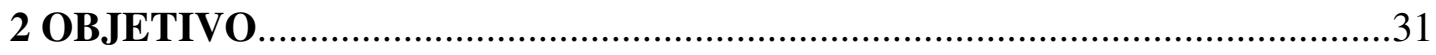

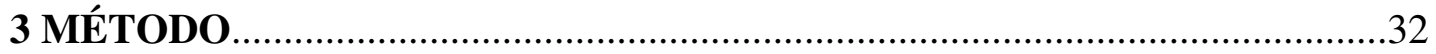

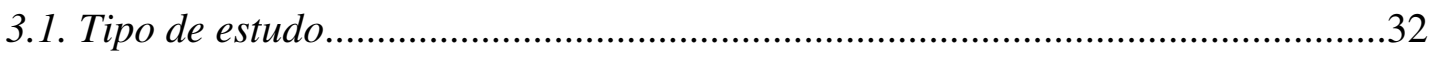

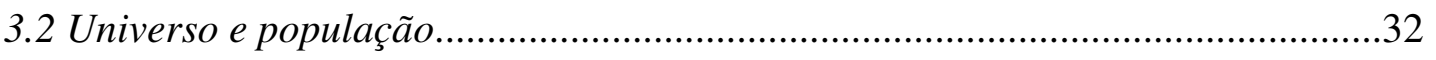

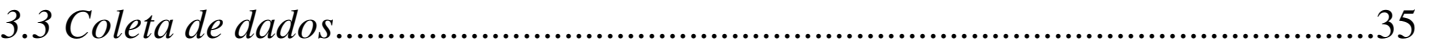

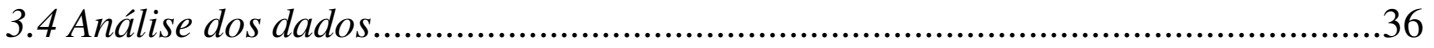

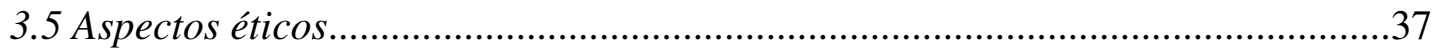

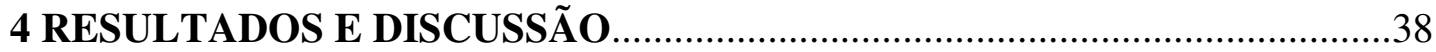

4.1 Caracterização das instituições de saúde e das enfermeiras obstétricas..............38

4.2 Atuação da enfermeira obstétrica na assistência ao parto e inserção

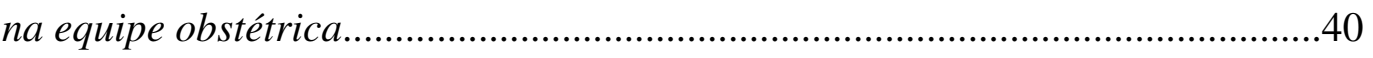

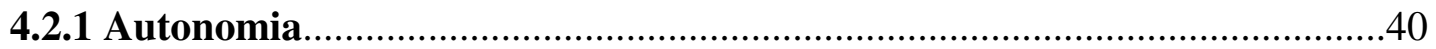

4.2.2 Confiança e cumplicidade: principais facilitadores da autonomia............43

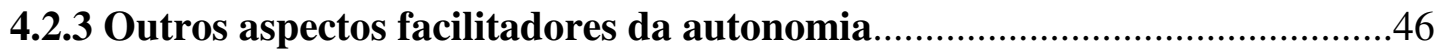

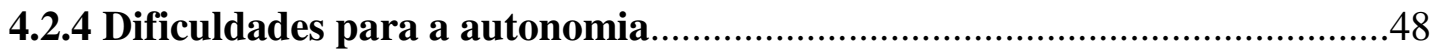

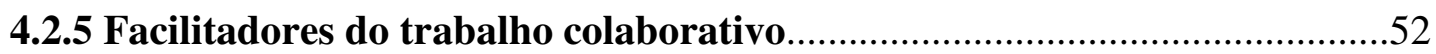




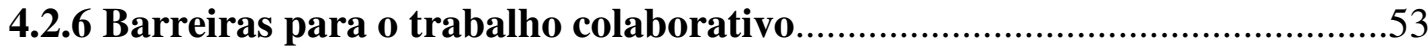

4.2.7 Percepção da inserção da enfermeira obstétrica na equipe........................60

4.2.8 Composição e coordenação da equipe de assistência ao parto....................64

4.2.9 Reflexões sobre a atuação da enfermeira obstétrica nas instituições de

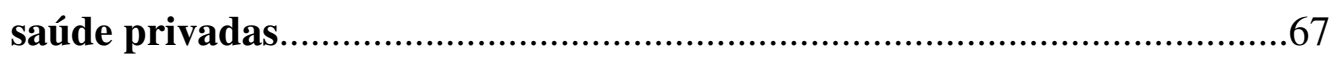

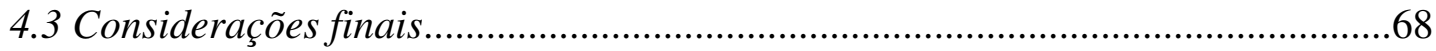

REFERÊNCIAS BIBLIOGRÁFICAS

ANEXOS 


\section{APRESENTAÇÃO}

Há 15 anos atuo na área de assistência obstétrica, acompanhando mulheres grávidas, clientes de uma clínica privada em São Paulo. Compomos uma equipe formada por três médicos obstetras, dois médicos pediatras, duas psicólogas e por mim, enfermeira obstétrica (EO). Coordeno, com a colaboração dos pediatras e psicólogas, um curso de preparação para o parto para casais e trabalho com grupos de gestantes, para a conscientização corporal. Quando necessário, realizo consultas individuais com mulheres que moram no interior do Estado e querem obter mais informações sobre o processo da maternidade, ou com aquelas que não puderam comparecer ao grupo de gestantes. Esta é também uma forma de nos conhecermos.

Assim que a internação da parturiente na maternidade é confirmada, sou chamada por um dos obstetras e permaneço junto à parturiente durante todo o trabalho de parto e parto. Ainda durante a internação e após o parto, visito a puérpera na maternidade, acompanho a adaptação às mamadas e a sua recuperação como um todo. Já em casa, a psicóloga da equipe faz uma visita domiciliar para ajudar a mulher à "fechar" o período da gravidez e parto e "iniciar" o período de pós-parto. Eu permaneço em contato com a puérpera, por telefone, e a consulta no pós-parto é realizada pelos obstetras.

Considero que há um trabalho colaborativo nesta equipe, porque as decisões - uso de indução, posição no parto, momento da analgesia entre outras - são analisadas e discutidas em conjunto e sempre levamos em consideração o bem-estar da parturiente e a vitalidade fetal. Posso afirmar, assim, que, da mesma maneira que existe uma parceria entre os membros da equipe, existe também entre a equipe e as parturientes. A minha interação como EO junto à parturiente e os acompanhantes promove maior confiança da mulher em si mesma, em relação a suas inquietudes e medos relacionados ao parto. 
Minha prática profissional permite-me observar o trabalho das EO em três maternidades privadas de São Paulo. Presencio que muitas EO se queixam de não poderem desenvolver a profissão com autonomia e do fato de que o trabalho colaborativo nem sempre acontece. As EO obedecem às orientações médicas, assumem funções e responsabilidades burocráticas e, com isto, ficam distantes do cuidado direto às gestantes, parturientes e puérperas.

Por meio de conversas com as EO e observação do trabalho delas, posso identificar um sentimento de frustração, por não conseguirem desenvolver a profissão plenamente. Freqüentemente, estão às voltas com papéis, escalas, reuniões, entre outras tarefas, e não têm a oportunidade de acompanhar de perto todo o trabalho de parto e de participar mais ativamente da assistência à mulher no período do trabalho de parto, parto e pós-parto. Além disso, as mulheres, na sua maioria, são precocemente submetidas à cesariana e, portanto, nem entram em trabalho de parto.

As EO trabalham para facilitar a assistência dos médicos obstetras, seguem rigorosamente os protocolos estabelecidos pelas instituições, e não têm tempo para prestar um atendimento individualizado às mulheres. Acredito que, se as EO desses serviços tivessem uma inserção efetiva na assistência obstétrica, com atribuições de controlar o trabalho de parto e parto e a assistência às mulheres no período pós-parto, em colaboração com a equipe médica, minha atuação com EO "independente", que não integra a equipe de enfermagem da instituição, seria dispensável ou desnecessária. Considero que parte do meu trabalho destina-se a "suprir a ausência" de EO atuantes nas maternidades privadas. 


\section{INTRODUÇÃO}

\subsection{Atuação e formação profissional das parteiras, obstetrizes $e$ enfermeiras obstétricas ${ }^{1}$}

A atuação profissional da parteira no Brasil teve início no período colonial. Naquela época, a parteira deveria se submeter a um exame para obter a "Carta de Examinação" e receber autorização legal para exercer a profissão. ${ }^{1}$

Os conhecimentos que possuía eram aqueles internalizados ao longo de sua experiência de vida como mulher e suas vivências pessoais de parto. Trabalhava sozinha ou com ajuda de uma mulher mais jovem, que dava continuidade à profissão. $^{2}$

Por meio de seu trabalho, as parteiras eram reconhecidas pelas mulheres e tinham intimidade com elas, chegando a ter acesso a segredos da família. Conheciam bem as necessidades femininas e realizavam os partos em troca de alguma remuneração ou doação. Também tinham grandes conhecimentos do uso de plantas medicinais e curativas como forma profilática de doenças e complicações no parto e no cuidado dos bebês. ${ }^{2,3}$

A formação acadêmica do médico no Brasil, iniciou-se a partir do século XIX, quando poucos médicos se interessavam pela obstetrícia, considerando-a um trabalho "sujo", sem valor. Apesar da desqualificação do "oficio de partejar", as parteiras eram bem quistas e respeitadas pelas parturientes. No entanto, entre os médicos, em especial, os cirurgiões, a experiência prática e o saber empírico das parteiras passaram ser percebidos como conhecimentos incômodos e temidos e, elas se tornaram um alvo fácil às críticas e difamações. ${ }^{2,3}$ As parteiras passaram a ser responsabilizadas pela elevada taxa da morbidade e mortalidade materna e infantil e denunciadas por prática ilegal devido à falta de uma formação formal e oficial.

Para se resguardar, muitas parteiras começaram a consultar um médico,

\footnotetext{
1 Os termos parteira, obstetriz e enfermeira obstétrica são usados, indistintamente, para designar profissionais não-médicos que assistem o parto, independentemente do sexo.
} 
quando havia complicações no desenrolar do nascimento de um bebê e, gradativamente, a presença do médico, que no começo era percebida com temor porque significava que havia perigo para a vida do bebê ou da mulher, passou a ser bem-vinda pelas mulheres. O conhecimento teórico e científico dos médicos transmitia segurança e eles, gradualmente, ganharam a confiança da sociedade, como um todo. No entanto, nem sempre o conhecimento e atuação dos médicos fazia grande diferença, em termos de taxas de mortalidade; havia os médicos charlatões e aqueles sem experiência prática e sem conhecimento algum. ${ }^{2,4}$

A partir de 1832, foram criados cursos para a formação de parteiras, ligados às faculdades de medicina. Para o ingresso no curso, era exigido das candidatas conhecimentos em português, matemática e francês e o consentimento dos pais, quando solteira, ou do marido, quando casada. No início, poucas parteiras se formaram, visto que era muito difícil para uma mulher, naquela época, ter acesso à educação e a permissão para trabalhar

A partir do século $\mathrm{XX}$, os partos, que eram atendidos no domicílio, foram sendo transferidos para o hospital, local que no início acolhia pessoas pobres, sem conforto ou segurança para a mãe e o recém-nascido. A hospitalização do parto foi uma maneira que os médicos encontraram para aprimorar o estudo e o aprendizado da obstetrícia e novas técnicas e instrumentos foram desenvolvidos, como a episiotomia, o fórcipe, a indução do parto e a anestesia. ${ }^{5}$ Desta maneira ,as mulheres, principalmente aquelas que residiam nas grandes cidades, passaram a dar à luz nos hospitais.

Paulatinamente, o hospital foi sendo considerado uma instituição eficaz e segura para a prática obstétrica. As mulheres aceitaram cada vez mais a presença do médico que, por poder recorrer rapidamente a medicamentos ou à cirurgia, inspirava confiança. ${ }^{5}$ Para garantir seres humanos perfeitos e sadios, a mulher deveria ser cuidada pelo que havia de melhor na medicina; o médico passou a ser considerado o melhor profissional para dar assistência à parturiente e ao recém nascido no processo do parto.

Nesse contexto, o parto, que era um acontecimento natural e fisiológico, passou a ser considerado pela população em geral como um acontecimento arriscado, "patológico" que necessitava de diagnóstico e controle e deveria ser acompanhado por médicos, com intervenções para garantir um desfecho saudável. ${ }^{6}$ 
A disseminação do médico obstetra na assistência ao parto aconteceu em meados do século XX. No mesmo período, houve um expressivo desenvolvimento de conhecimentos e habilidades na cirurgia, anestesia, assepsia, hemoterapia e antibioticoterapia, promovendo a redução da morbidade e mortalidade maternas e infantis. ${ }^{7}$ O parto em ambiente hospitalar reforçou a premissa da assistência do médico ser considerada mais segura para o binômio que a atenção e cuidados de uma parteira. $^{8,9}$

A profissão de parteira foi, então, sofrendo um declínio importante. O seu status social, a vinculação com a comunidade e com as mulheres e o seu campo de atuação foram diminuindo gradativamente, na medida em que tiveram suas atividades delimitadas pelos conhecimentos e intervenções dos médicos. ${ }^{5}$ As suas responsabilidades e atividades no hospital passaram a ser principalmente cuidar da puérpera e do recém-nascido, ${ }^{10}$ bem como gerenciar as unidades de internação.

Assim, o desaparecimento da antiga profissão de parteira até quase a extinção não ocorreu por acidente. Não foi apenas com a intenção de melhorar a qualidade do cuidado materno e fetal que ocorreu a institucionalização do parto, mas sim, devido a uma tentativa de eliminar a competição econômica entre médicos e parteiras. Para atingir este objetivo, o corporativismo médico começou a agir em duas frentes: propaganda para desacreditar a prática e a reputação das parteiras e conquistar apoio da população, além de legislar e regular a atividade dessas profissionais e manter o monopólio e o poder sobre elas., 3,11

Quanto ao ensino da parteira, foram várias as modificações ocorridas. O título de parteira foi substituído pelo de obstetriz ou enfermeira obstétrica (EO), sendo que a partir da década de 1960, as faculdades de medicina deixaram de se interessar em formar essa profissional e transferiram a sua formação para as escolas de enfermagem. ${ }^{5}$

Durante as décadas seguintes, entre 1970 e 1990, a participação da EO na assistência ao parto ficou restrita, com um número limitado de profissionais atuando nas diferentes regiões do País. De 1977 a 1997, haviam se formado, no Brasil, apenas 2.756 EO, por 19 escolas, sendo a maioria no Estado de São Paulo. ${ }^{12}$ No final da década de 1990, o Ministério da Saúde (MS) passou a oferecer apoio técnico e financeiro a cursos de especialização em EO, que contribuíram de forma expressiva na formação de novos profissionais. Entre 1999 e 2000, formaram-se 1.041 EO, 
sendo que $51 \%$ delas estavam atuando diretamente no centro obstétrico, e as demais trabalhando no pré-natal, no puerpério, ou em outras áreas. ${ }^{12}$

Entre 2005 e 2007, 1.929 médicos foram aprovados e obtiveram o Título de Especialista em Ginecologia e Obstetrícia, da Federação Brasileira das Associações de Ginecologia e Obstetrícia (Febrasgo). ${ }^{13}$ Apesar dos dados levantados não corresponderem ao mesmo período, é possível observar que o número de médicos formados é maior que o de EO. Esta realidade confirma a dominação médica na assistência ao parto, durante todo este tempo, e a quase invisibilidade de presença da EO, tanto para os médicos como para a sociedade em geral.

\subsection{A formação da obstetriz ou enfermeira obstétrica na atualidade}

Atualmente, a formação da obstetriz ou EO pode acontecer no Brasil por duas vias: quatro anos de formação superior em enfermagem, seguidos de um ano de especialização em enfermagem obstétrica, conferindo à enfermeira o título de $\mathrm{EO}$, ou a entrada direta para a formação em obstetrícia, graduando obstetrizes após quatro anos. Esta última modalidade, implantada em 2005, no Campus Leste da Universidade de São Paulo (USP) teve o apoio da Escola de Enfermagem da USP e ainda não formou a primeira turma.

Durante a formação, tanto teórica como prática, as EO não têm contato direto com os médicos, e por isso eles pouco conhecem as atribuições e contribuições de cada um para a assistência obstétrica às mulheres. A formação médica é muito isolada da formação das EO, apesar do campo de atuação ser comum aos dois profissionais.

A graduação médica no Brasil acontece em seis anos, seguidos de residência na especialidade escolhida, de três anos, no caso da ginecologia e obstetrícia. A formação dos médicos enfatiza o diagnóstico e tratamento das doenças e o uso de intervenções, que são consideradas de maior importância, principalmente nas gestações de alto risco. Apesar de a gestação de baixo risco ser um processo que geralmente transcorre sem complicações, inclusive no parto, os estudantes de medicina são treinados para adotar "práticas rotineiras", como numa linha de 
produção, sem a avaliação crítica caso a caso. Disto decorre um grande número de intervenções desnecessárias e potencialmente iatrogênicas. ${ }^{14,15}$ A supervisão dos médicos durante o treinamento em serviço indica, para os alunos, a valorização da perícia na realização de intervenções operatórias na assistência ao parto e, freqüentemente, a aluna de enfermagem obstétrica está presenciando essa atitude. A interação pessoal dos alunos de medicina com as pacientes não é valorizada pelos professores e tampouco pelos estudantes. Estes são considerados espaços de atuação de profissionais não-médicos, nos casos de evolução considerada normal. ${ }^{15}$

Prestar cuidados humanizados e baseados em evidências científicas - como por exemplo para o alívio da dor - e estudar a variabilidade daquilo que é normal é considerado pouco importante, como uma atitude menor, que fica a encargo das alunas de EO. Esse desprestígio das funções das EO nos cuidados às necessidades básicas das mulheres provavelmente tem repercussões, não apenas na formação dos alunos de medicina, mas também na formação das EO. Elas percebem que suas atividades são pouco valorizadas pelo modelo assistencial, contribuindo para a perpetuação da sua não-valorização, para o pouco reconhecimento das atribuições da EO e para a hierarquização das relações profissionais.

Quando as EO ingressam no mercado de trabalho, levam consigo o aprendizado que tiveram, ou seja, com limitações da sua autonomia e pouca cooperação com os médicos, que acreditam que a EO tem pouco a contribuir e não confiam nas suas competências. ${ }^{16} \mathrm{O}$ médico obstetra enfatiza a sua autoridade e autonomia profissional baseado no seu saber técnico. ${ }^{17}$ Desta maneira, a formação da EO, distante da formação médica, contribui também para com o consentimento da subordinação através da aceitação da hierarquia baseada na valorização das intervenções médicas e em oposições de gênero, posto que, na grande maioria, as EO são mulheres.

Payne $^{18}$ descreveu, em seu trabalho, uma tentativa de treinar em conjunto EO e médicos, dando a eles a oportunidade para aprender a prestar cuidados. Essa experiência resultou na diminuição de práticas intervencionistas após a formação, porque houve a cooperação entre as duas disciplinas. Cada um aprendeu a respeitar o outro pelos conhecimentos complementares que possuem para melhorar o cuidado às mulheres e seus bebês. O autor reconhece que há diferenças culturais entre as EO e os médicos e que são necessárias estratégias de comunicação para que elas sejam 
superadas. No entanto, essas diferenças podem ser vistas como oportunidade para que os cuidados às mulheres se tornem cada vez mais completos através da colaboração.

É inegável que a inserção do médico na assistência às mulheres e a institucionalização do parto trouxeram resultados positivos, porém vieram acompanhados de importantes efeitos colaterais, como a medicalização e tecnologização da assistência ao nascimento.

No processo de transferência do parto domiciliar atendido por parteiras para o hospital com a atenção médica, a mulher, parturiente ou puérpera, tomou para si a atitude ser paciente, submissa aos cuidados médicos. As intervenções nem sempre são explicadas e a mulher foi afastada, cada vez mais, do seu papel de protagonista da cena do parto, tornando-se um elemento passivo e secundário no seu próprio processo de parturição. Esta é uma realidade que perdura até hoje. ${ }^{14}$ Os médicos continuam sendo considerados os mais preparados para atender o parto e são aqueles que "sabem o que estão fazendo". A EO é a sua auxiliar, submentendo-se ao seu comando, e a mulher deixou de entender o que acontece consigo.

\subsection{Gênero, poder e assistência ao parto}

Ao analisarmos historicamente a noção de gênero, podemos observar que existem relações de poder e hierarquia entre os sexos. Essa hierarquia de gênero e poder é caracterizada pela dominação histórica dos homens perante as mulheres.

A diferenciação histórica entre homens e mulheres culminou com atribuições características de cada um. Ao homem couberam as tarefas ligadas ao perigo físico, conquistas territoriais à dominação e ao jogo de poderes sobre os outros, tratando-os como objetos. À mulher couberam as tarefas relativas ao cuidado e à produção, conservação e desenvolvimento da vida, centradas nas relações pessoais, sensíveis ao universo simbólico e espiritual, capazes de empatia e comunhão com o outro.

Assim, o homem tornou-se dominador da sociedade. Passou a dominar a mulher, tornando-a subalterna, submissa e obediente, caracterizando o patriarcado, que também foi o precursor para o machismo e a veneração do masculino. Esta 
construção social declarou a mulher como ser submisso, inferior e enfermo com uma remuneração inferior ao homem, mesmo exercendo as mesmas tarefas.

O movimento feminista que se organizou a partir da década de 1970, no Brasil, trouxe mudanças, contribuindo para a diminuição das diferenças entre os gêneros. Foram várias as conquistas nas esferas políticas, educacionais e também de assistência à saúde. Porém, no campo de trabalho, a hierarquia de gênero ainda acontece e pode ser percebida através das diferenças salariais para executar as mesmas funções, valorizando mais o trabalho do homem.

A enfermagem obstétrica é uma profissão basicamente feminina desde a sua gênese e, ao analisar a trajetória histórica da profissão e da formação utilizando a categoria gênero, é possível identificar a submissão, passividade e subserviência à hegemonia médica. Gênero, poder e liderança estão interligados. Existem pesquisas que mostram que as mulheres vêem o poder diferentemente do homem e essa situação dificulta a percepção de que elas também possuem um poder. ${ }^{16,19}$ Este é provavelmente um dos grandes desafios a serem conquistados pela enfermagem brasileira na atualidade.

Independentemente do número de mulheres médicas na área obstétrica, a prática da maioria dessas profissionais responde a padrões e modelos masculinos de atenção. Assim, existe uma expectativa de que o(a) médico(a) obstetra atue conforme estereótipos masculinos: independentes, dominantes, racionais, insensíveis, autoconfiantes. $^{5}$

A relação profissional do médico com a EO no Brasil é de poder, com o médico na condição de chefe responsável pela coordenação da assistência ao parto. ${ }^{11}$ O papel social de subordinação das mulheres se reproduz no espaço privado (família), como também profissional. A exclusão do papel feminino na sociedade contribuiu na reprodução das relações de poder de dominação-submissão até hoje presentes no setor de saúde. O início da enfermagem profissional ocorreu respeitando os paradigmas sociais da produção capitalista e se organiza dentro desses preceitos no espaço hospitalar. ${ }^{10}$ As decisões das EO geralmente são dependentes de autorizações e consentimento dos médicos. ${ }^{11}$

O reconhecimento da importância do trabalho das enfermeiras ocorre naquilo que se refere à equipe, e não à paciente, e que tem a ver com as suas atribuições. Nas instituições privadas, a EO tem a função de manter a comunicação entre "as clientes" 
e o corpo médico, fazer orientações quanto aos cuidados, zelar pelo bem-estar do binômio mãe-filho, pelo conforto dentro da instituição ou dar seqüência a exames e encaminhamentos solicitados. ${ }^{20,21}$

\subsection{Assistência ao parto no Brasil}

Para compreender a maneira como a assistência à mulher durante o processo parto no Brasil ocorre é importante levar em consideração como a formação dos médicos, em relação à formação das $\mathrm{EO}$, é muito mais valorizada. $\mathrm{O}$ modelo predominante de dar à luz, no Brasil, ainda está ancorado nas atividades e decisões médicas e a maioria dos partos acontece em ambiente hospitalar. Em 2004, $97 \%$ dos partos ocorreram no hospital e, aproximadamente, $43 \%$ foram cesarianas. ${ }^{22} \mathrm{O}$ percentual de cesarianas na rede de assistência à saúde suplementar, portanto privada, foi de $81,7 \%$, em 2003 , e $82,4 \%$, em $2004 .^{23}$ Nos hospitais do município de São Paulo integrados ao Sistema Único de Saúde (SUS), o índice de cesarianas, em 2005 , foi de $31,7 \% .^{22}$

\subsubsection{A rede privada de assistência ao parto - Sistema de Saúde Suplementar}

A assistência de saúde no Brasil é feita nas redes pública, por meio do SUS, ou privada. Na rede privada, os serviços podem ser adquiridos por meio de seguro de saúde ou de plano ou convênio de saúde. Esse setor de prestação de serviços de saúde se expandiu significativamente nos anos 1980, e as regras que orientam seu funcionamento estão definidas na Lei n. 9.656/98 e na MP n. 2.177-44, atualmente em vigor. "O setor é regulado pela Agência Nacional de Saúde Suplementar (ANS), que tem por finalidade institucional promover a defesa do interesse público na assistência suplementar à saúde, regular as operadoras setoriais, inclusive quanto à sua relação com prestadores e consumidores e contribuir com o desenvolvimento das 
ações de saúde do País". ${ }^{24}$

Na modalidade de saúde suplementar definida como seguro de saúde, o cliente paga um valor mensal estabelecido pela seguradora para obter uma cobertura de serviços de saúde, num sistema de livre escolha, que varia de acordo com as suas necessidades e com os serviços contratados. Os seguros de saúde são regidos pela legislação de seguros e fiscalizados pela Superintendência de Seguros Privados e pela ANS. Nos planos ou convênios de saúde, o usuário contrata uma série de serviços e direitos, especificados por contrato, regulamentados por leis específicas e fiscalizadas pela ANS, porém sem livre escolha de hospitais e profissionais.

No Brasil, existem aproximadamente 2.000 empresas operadoras de planos, convênios e seguros de saúde e uma enorme rede de prestadores de serviços, entre clínicas, hospitais, laboratórios, médicos e outros profissionais. Informações da ANS indicam que o Brasil possui 37 milhões de consumidores que utilizam os seguros ou convênios de saúde para realizar consultas, exames ou internações, ${ }^{24}$ o que equivale a uma taxa da cobertura de $20,3 \%$ da população. ${ }^{25}$

$\mathrm{Na}$ cidade de São Paulo, existem maternidades privadas com diversas estruturas administrativas. Essas instituições atendem à clientela de planos ou convênios e particulares, com ou sem seguro de saúde. As instituições filantrópicas também atendem clientes com planos ou convênios de saúde e particulares, assim como clientes do SUS. As instituições públicas municipais e estaduais fazem o atendimento à população através do SUS. Segundo o cadastro nacional de estabelecimentos de saúde, a rede hospitalar do município de São Paulo tem 2829 leitos obstétricos distribuídos em 1631 leitos SUS e 1198 leitos não-SUS. ${ }^{26}$

Nas instituições privadas, o vínculo de trabalho da EO é o de funcionária da instituição, com jornada de seis a oito horas de trabalho diárias ou no regime chamado de 12 x 36 (jornada de 12 horas de trabalho, seguidas por 36 horas de descanso), e uma remuneração mensal fixa. Nas instituições com "corpo clínico aberto", os médicos, em geral, não são funcionários da instituição, atendem gestantes de sua clínica particular, recebendo exclusivamente pelos procedimentos realizados, pagos pelas seguradoras ou empresas de planos ou convênios de saúde. Nas instituições que atendem exclusiva ou majoritariamente mediante plano ou convênio de saúde, o regime de contratação dos médicos usualmente é diferente: eles são funcionários, trabalhando em regime de plantões de 12 ou 24 horas. É comum que 
cada médico trabalhe em vários plantões por semana, em hospitais diferentes.

A maioria das EO trabalha em maternidades, ligadas ou não a hospitais gerais. São poucas as EO que exercem sua profissão em casas de parto ou de maneira independente, em atendimento domiciliar. ${ }^{27} \mathrm{O}$ Conselho Regional de Enfermagem e a Associação Brasileira de Obstetrizes e Enfermeiros Obstetra (Abenfo) não dispõem da informação sobre a distribuição dos enfermeiros formados no País, conforme área de atuação.

\subsubsection{Movimento pela humanização do parto}

O índice de cesarianas no País vem crescendo desde a década de 1980, e na década seguinte chamou a atenção da mídia e do MS. Em 1993, foi criada a Rede pela Humanização do Parto e Nascimento (Rehuna), organização de pessoas leigas e profissionais da saúde preocupados com o aumento da medicalização da assistência ao parto. ${ }^{28}$ Em 1994, foi criada a Abenfo, com seccionais em todas as regiões do Brasil, que ajudou a reorganizar a profissão das EO e obstetrizes. Com a intenção de diminuir as intervenções obstétricas desnecessárias e o número elevado de cesarianas, o MS vem implementando uma série de medidas para estimular o parto normal, bem como o processo de humanização da assistência obstétrica. Regulamentou a realização do parto normal pela EO através da Portaria GM n. 2.815/98. ${ }^{29}$ Com outra Portaria, a GM n. 985/99, criou os Centros de Parto Normal, definindo o papel da EO nesses serviços. ${ }^{30}$ Nesse ambiente, a assistência à mulher e ao recém-nascido pode ser realizada pela EO, independentemente da presença do médico, reconhecendo a legalidade, legitimidade, especificidade e autonomia de profissão, em conformidade com lei do exercício profissional (Lei n. 7.498/86 e Decreto n. 94.406/87) $)^{31}$ e as recomendações da Organização Mundial da Saúde (OMS). ${ }^{32}$

Iniciou-se, na década de 1990, a busca por uma assistência mais humanizada à mulher no parto e várias instituições tomaram iniciativas para humanizar a assistência. Essas mudanças atingiram todos os profissionais envolvidos no processo do parto e pós-parto, como EO, médicos obstetras e pediatras, administradores dos 
serviços públicos e privados e usuárias, propondo ou impondo novos papéis para cada um no processo do parto.

Desde então, vêm sendo gerados debates acadêmicos e litígios jurídicos, em relação ao modelo proposto e ao profissional mais adequado para prestar assistência no pré-natal e parto. ${ }^{9}$

Em 2000, ocorreu um movimento de cooperação entre o MS, a Febrasgo e a Abenfo, a fim e colocar em prática as recomendações da OMS para a assistência ao parto normal. Houve produção e distribuição de material educativo para todos as maternidades e clínicas. $^{25}$

Embora o conceito de parto humanizado apresente variações, a expressão "parto humanizado" pode ser usada para os partos em que a mulher é respeitada nas suas preferências: ela fica com o acompanhante de sua escolha, pode se movimentar à vontade, toma líquidos ou alimentos leves, escolhe a posição para parir sua criança. No parto humanizado, a mulher é poupada de intervenções que podem ser desnecessárias, tais como: soro para apressar o parto, lavagem intestinal, raspagem dos pêlos pubianos, episiotomia ou jejum. O MS, através da Portaria GM n. 569/00, instituiu o Programa de Humanização do Pré-Natal e Nascimento com o objetivo de assegurar o acesso e a qualidade da assistência pré-natal, ao parto, pós-parto e neonatal. Definiu também que, por parte dos profissionais, humanização é receber com dignidade a mulher, seus familiares e recém-nascido, exercendo uma atitude ética e solidária, de modo a criar um ambiente acolhedor e a instituir rotinas hospitalares que rompam com o tradicional isolamento imposto à mulher, além de evitar práticas intervencionistas desnecessárias, que não beneficiam a mulher e o recém-nascido e que podem acarretar riscos para ambos. ${ }^{29}$

Estudos científicos nacionais e internacionais comprovam que com a presença de acompanhantes, as mulheres se sentem mais seguras e se reduz a incidência de depressão pós-parto. Humanizar o parto significa dar assistência à mulher com base em evidências científicas, ou seja, com "o uso consciente, criterioso e explícito das melhores evidências atuais para tomar decisões sobre o atendimento a pacientes individuais". ${ }^{33}$ As evidências de pesquisas devem ser usadas para orientar o tratamento e não para determiná-lo em todos os casos. Para Osava, ${ }^{5}$ a maioria das rotinas hospitalares não é questionada e muitos procedimentos precisam ser revistos. 
No caso da assistência ao parto, cada vez mais as práticas consideradas "de hábito" e fundamentadas só na experiência ou em achados empíricos têm sido combatidas.

A massagem, deambulação, banho de chuveiro ou de imersão fazem parte do suporte à mulher, pois são formas de fazer com que haja bem-estar, relaxamento físico e conforto. Portanto, esse tipo de suporte à mulher exige das EO modificações nas suas atividades para que possam despender mais tempo dando amparo às mulheres. ${ }^{33}$ Hodnett $^{34}$ revela que as atitudes e o comportamento dos profissionais envolvidos com a mulher no parto são considerados mais importantes pelas parturientes do que as intervenções realizadas ou métodos de alívio da dor adotados.

\subsection{Autonomia profissional e o trabalho colaborativo da enfermeira} obstétrica na assistência ao parto

\subsubsection{Autonomia}

Os temas autonomia profissional e trabalho colaborativo da EO são abordados sob diferentes aspectos nas publicações internacionais. Fleming ${ }^{20}$ rejeita a idéia de que as EO tenham autonomia no exercício de sua profissão. A autora reforça que há uma falta de discussões mais profundas sobre o assunto, muito embora a OMS tenha o entendimento de que as EO têm autonomia para trabalhar e são o profissional mais indicado para atender as gestações e partos normais de baixo risco, incluindo o acompanhamento de situações de risco e o reconhecimento de complicações. ${ }^{35}$ Por outro lado, a OMS também reconhece que, na maioria dos países industrializados, a função das EO nos hospitais está sob supervisão de médicos. ${ }^{32}$ Isso quer dizer que os cuidados para todo tipo de parto fazem parte dos mesmos departamentos de obstetrícia, com pouca distinção entre gestações de baixo risco e alto risco, deixando para os médicos todos os procedimentos e decisões, enquanto que a enfermeira apenas promove um cuidado qualitativo de conforto. ${ }^{36}$

A maioria das EO continua trabalhando em locais onde há claramente esse domínio médico. A medicalização do atendimento obstétrico restringiu a autonomia 
da EO à medida em que ela deve seguir as orientações médicas e institucionais. ${ }^{36}$ São poucas aquelas que fazem o atendimento domiciliar de maneira independente ou que desempenham a sua função com mais autonomia, mesmo dentro das instituições e, por isto, esta discussão torna-se necessária.

Autonomia é definida como: "1. Faculdade de se governar por si mesmo; 3. Liberdade ou independência moral ou intelectual; 5. Condição pela qual o homem pretende poder escolher as leis que regem a sua conduta". ${ }^{37}$ Todas estas definições são relacionadas entre si. É difícil definir o tema autonomia no complexo e amplo contexto no qual as EO trabalham. A autonomia pressupõe determinado grau de poder, conhecimento teórico e prático, reconhecimento do ambiente de atuação, competências para fazer escolhas, e a capacidade para agir, decidir e responsabilidade na tomada de decisões. Pode ser também descrita como a liberdade de atuar, levando em consideração os protocolos de atuação e parâmetros da enfermagem, para oferecer o melhor atendimento às mulheres. A competência e a responsabilidade para a tomada de decisões necessitam de conhecimentos baseados em evidências, mobilizações, coragem intelectual e moral, além de comunicação clara para racionalizar uma situação., ${ }^{3,38,39}$ À medida que esses conhecimentos são reconhecidos e validados pelos outros profissionais envolvidos, assim como também pelas pessoas atendidas, a autonomia é favorecida.

A competência pode ser definida como uma capacidade de agir eficazmente em um determinado tipo de situação, apoiado em conhecimentos, mas sem limitar-se a eles. Desta forma, estabelece-se diferença entre competências e conhecimentos. Enquanto os conhecimentos são representações da realidade que construímos e armazenamos ao sabor da nossa experiência e da nossa formação, as competências são capacidades que trazemos da nossa experiência de vida, para os utilizar, integrar ou mobilizar, visando à solução dos diversos problemas com os quais nos deparamos diariamente. $^{40,41}$ A definição de competências, conforme a Confederação Internacional das Parteiras (ICM), ${ }^{35}$ é um conjunto de conhecimentos ou habilidades clínicas que as EO devem possuir para que possam praticar a profissão de maneira efetiva e com segurança.

O documento sobre as "Competências Essenciais para o Exercício Básico da Obstetrícia", publicado em 2002, pela ICM, enumera seis amplas competências que o profissional deve possuir: ${ }^{42}$ 
Competência 1: as parteiras têm conhecimento e habilidades das áreas de ciências sociais, saúde pública e ética que constituem a base do cuidado de alta qualidade, culturalmente apropriado para as mulheres, recém-nascido e família, no período reprodutivo;

Competência 2: as parteiras fornecem educação para a saúde de alta qualidade e culturalmente sensível, proporcionam serviços para toda a comunidade para promover uma vida familiar saudável, gestações planejadas e uma maternidade/paternidade positiva;

Competência 3: as parteiras proporcionam um cuidado pré-natal de alta qualidade, preocupadas em otimizar a saúde da mulher durante a gravidez, e isso inclui a detecção precoce, tratamento ou encaminhamento de algumas complicações;

Competência 4: as parteiras proporcionam, durante o parto, um cuidado de alta qualidade, culturalmente sensível. Conduzem um parto higiênico e seguro e manejam situações de emergência para otimizar a saúde das mulheres e dos recémnascidos;

Competência 5: as parteiras proporcionam à mulher cuidado integral, de alta qualidade, culturalmente sensível, durante o pós-parto;

Competência 6: as parteiras proporcionam cuidado integral de alta qualidade para o recém-nascido saudável, do nascimento até dois meses de idade.

Cada um desses seis enunciados traz uma lista de conhecimentos e habilidades básicas exigidas para uma prática segura em qualquer situação; eles determinam também os conhecimentos e habilidades adicionais, que podem ser adotados ou não, de acordo com a realidade de cada país. Esse documento aponta as competências essenciais para a prática das parteiras que, no nosso caso, se aplicam às EO, com o objetivo de fornecer um entendimento comum a todos os profissionais, educadores e responsáveis pela política de saúde, quanto às habilidades e práticas que se pode esperar das EO, de acordo com as definições internacionais. As competências essenciais podem servir como base para a formação curricular das EO.

Estabelecidas as competências da EO, a autonomia profissional foi analisada por pesquisadores internacionais que destacaram os resultados do empoderamento das EO e concluíram que as conseqüências positivas do exercício da profissão com autonomia são o aumento da auto-estima e autoconfiança das profissionais e uma assistência com melhor qualidade, com o reconhecimento dos seus direitos e deveres 
perante as clientes e os outros profissionais envolvidos. Quando a EO tem a oportunidade de mostrar o conhecimento técnico e a sua habilidade, ela pode firmar o seu papel dentro da equipe obstétrica, conquistar e estabelecer uma relação saudável e igualitária., 36,36,38,43

Pollard $^{38}$ desenvolveu um esquema para a compreensão da autonomia na prática das EO, levando em consideração as barreiras, as situações facilitadoras, as condições e os desfechos para a atuação com autonomia. Ao aplicá-lo ao ambiente do serviço, verificou que as barreiras para a atuação com autonomia são as políticas médicas e hospitalares, o pouco reconhecimento profissional e a hierarquia hospitalar, enquanto que a situação facilitadora é trabalhar por conta própria.

As condiçõos para a autonomia apontadas são: ter uma compreensão madura sobre o conceito; conhecer bem o ambiente da sua prática; ter a autoridade para tomar decisões e agir; ter o reconhecimento, pelas usuárias e outros profissionais, do direito e da competência da sua prática. Quanto aos desfechos, são mencionados: melhor qualidade de assistência para as mulheres, gestantes, parturientes ou puérperas; maior satisfação profissional, maior confiança no conhecimento, nas atividades e nas habilidades das enfermeiras obstétricas. ${ }^{38}$

\subsubsection{Colaboração na assistência ao parto}

Para trabalhar de maneira autônoma, é necessário que, além dos fatores citados acima, exista a colaboração entre as EO e os médicos obstetras, além dos outros profissionais envolvidos, como médicos pediatras, anestesistas e neonatologistas. ${ }^{35}$ Os pré-requisitos para uma atuação com autonomia incluem, além da competência, conhecimento, liberdade para agir e confiança, o apoio da chefia de enfermagem. Através da motivação, reconhecimento e apoio na atuação, a enfermagem se fortalece para desempenhar suas funções com mais autonomia. Porém, as EO ainda têm dificuldades para compreender e consolidar a sua profissão com autonomia e na colaboração com os outros profissionais envolvidos. Esta limitação da compreensão pode, em parte, acontecer devido à pouca distinção entre as funções das EO e dos médicos, rendendo à EO uma posição de quase 
invisibilidade para o público. ${ }^{20,43}$

As EO necessitam da presença dos médicos para desenvolver um trabalho em conjunto, colaborativo, por exemplo para consultas, recomendações e discussões de casos, quando se deparam com alguma situação de risco para a gestante parturiente ou puérpera. ${ }^{20,35}$ Colaboração significa: 1. Trabalho em comum com uma ou mais pessoas. ${ }^{37} \mathrm{O}$ trabalho colaborativo acontece quando todos os profissionais envolvidos na equipe reconhecem e respeitam o valor individual e profissional de cada parte, e pode ser caracterizado por vários aspectos, como comunicação efetiva e clara, diálogo verdadeiro, ouvir ativo e habilidade para negociar. Responsabilidade, competência e assertividade são comportamentos centrais para estabelecer um relacionamento de respeito entre $\mathrm{EO}$ e médicos obstetras e com todos os profissionais envolvidos no cuidado às mulheres e aos seus bebês. ${ }^{44,45}$

O trabalho colaborativo também pode ser entendido como "trabalhar junto", em cooperação, preservando a saúde, educando, cuidando e medicando. É o trabalhar junto com metas e objetivos comuns. Embora, historicamente médicos e enfermeiras estejam juntos, tanto no trabalho hospitalar como no comunitário, poucas vezes seguem os mesmos caminhos. Nem sempre estão colaborando e cooperando e é comum observar uma certa competição, buscando cada um a seu modo dar o melhor ao cliente ou à instituição. Existe uma sobreposição de conhecimentos e por isso a delimitação e a diferenciação entre as funções de cada profissional freqüentemente não são claras. ${ }^{18}$

Para as EO, o comportamento colaborativo inclui respeito, confiança e apoio dos médicos obstetras nas suas atividades. Para os médicos, a competência clínica, o querer colaborar e a facilidade para interagir são considerados requisitos para um relacionamento colaborativo. ${ }^{44}$

A colaboração entre os profissionais reconhece a contribuição e importância de cada um e, conseqüentemente, garante a continuidade do atendimento, assegurando à mulher a integralidade da atenção. A cooperação entre o trabalho médico e o da EO está firmado em um tripé que consiste nos seguintes conceitos: conhecimento, habilidades e atitudes. Estes seriam aspectos indissociáveis para uma ação profissional de alto nível. ${ }^{46}$

A definição das atribuições profissionais de cada um e a confiança, associadas aos conhecimentos, às habilidades e às atitudes são condições importantes 
para que esse relacionamento colaborativo aconteça. Essas condições estão sempre juntas e permitem que se estabeleça uma base sólida para uma ação profissional de alto nível, "melhorando a qualidade da assistência, satisfação das clientes, com menos reclamações, uso do tempo com eficiência, menos tempo de internação, redução do número de intervenções desnecessárias e procedimentos invasivos e, conseqüentemente, reduzindo os custos para a instituição ou o sistema de saúde". ${ }^{16,44}$

As principais barreiras para que o trabalho colaborativo aconteça em uma equipe são a falta de compreensão dos papéis profissionais, assim como comunicação ineficiente e relações hierarquizadas. Essas barreiras criam uma atmosfera de competições, medo, falta de confiança, inseguranças e conflitos. ${ }^{44} \mathrm{~A}$ comunicação clara entre os profissionais quanto aos cuidados prestados, os procedimentos e informações sobre a paciente promovem a interação que se reflete no desempenho da equipe, favorecendo a qualidade da assistência prestada à paciente.

\subsection{Pressupostos}

- A atuação da enfermeira obstétrica (EO) na assistência ao parto é definida pelas políticas de saúde oficiais e pela organização da assistência praticada nas instituições.

- A forma como a EO na assistência ao parto e como vivencia a autonomia profissional e o trabalho colaborativo dependem do local de atuação, das regras e normas da instituição, da divisão técnica do trabalho e da relação hierárquica estabelecida na equipe obstétrica. 


\subsection{Objeto}

Este estudo tem como objeto a percepção da enfermeira obstétrica (EO) sobre a sua atuação na assistência ao parto e sua inserção na equipe obstétrica. Está relacionado à compreensão das relações de trabalho entre a EO e os membros da equipe, em especial, os médicos obstetras, contemplando os temas autonomia profissional da EO e trabalho colaborativo na assistência à mulher durante o trabalho de parto, parto e pós-parto. 


\section{OBJETIVO}

O objetivo do presente estudo é descrever como a enfermeira obstétrica percebe sua inserção na equipe obstétrica e sua autonomia profissional na assistência à mulher durante o parto, em instituições de saúde privadas. 


\section{MÉTODO}

\subsection{Tipo de estudo}

Para o desenvolvimento deste estudo, foi utilizada uma abordagem metodológica qualitativa, que possibilita compreender como a enfermeira obstétrica (EO) que atua em instituições de saúde privadas percebe a sua inserção e autonomia na assistência à mulher no parto e o relacionamento com a equipe obstétrica.

A pesquisa qualitativa caracteriza-se por se preocupar com a realidade que não pode ser quantificada e por aprofundar-se "no mundo dos significados das ações e relações humanas". A particularidade da pesquisa qualitativa é possibilitar ao pesquisador apreender a maneira pela qual os indivíduos pensam e reagem perante as questões formuladas, permitindo o aprofundamento dos significados. A essência da pesquisa qualitativa consiste na sua potencialidade de explicar os fenômenos e ampliar a compreensão destes por meio de conceitos analíticos. ${ }^{47}$

\subsection{Universo e população}

O universo do estudo foi constituído por EO que atuavam em instituições de saúde privadas da cidade de São Paulo que atendem exclusivamente pacientes particulares ou usuários de seguros ou planos de saúde.

As instituições de saúde privadas foram identificadas pelo Cadastro de Estabelecimentos de Saúde da Secretaria Municipal de Saúde da Prefeitura de São Paulo, em janeiro de 2007. ${ }^{48}$ Foram identificadas 86 instituições, cadastradas como hospitais privados. Em seguida, foi feito contato telefônico com cada uma destas instituições para obter informação sobre a existência de leitos obstétricos. Desse cadastro foram excluídas 63 instituições, considerando os seguintes motivos: 39 são hospitais gerais ou especializados sem leitos obstétricos; 12 não tinham EO no quadro de funcionários; cinco tinham o número de telefone incorreto ou ausente no 
Cadastro e não constavam do catálogo da empresa telefônica; cinco atendiam apenas usuários do Sistema Único de Saúde (SUS); em uma, a única EO do quadro de funcionários desempenhava a função de supervisora, sem prestar cuidados diretos a gestantes, parturientes e puérperas; em uma, a enfermeira responsável informou que todo o quadro de EO havia sido substituído, impossibilitando a realização de entrevistas, já que todas eram recém-contratadas na instituição.

Assim, 23 instituições foram selecionadas, considerando que prestavam atendimento obstétrico, com leitos de maternidade em suas instalações, com EO atuantes na assistência à mulher no pré-parto, parto e pós-parto.

Nessas 23 instituições, a autorização de realização da entrevista com a EO esteve condicionada ao envio de e-mail com uma sinopse da pesquisa e o parecer do Comitê de Ética em Pesquisa da Escola de Enfermagem da USP. Os e-mails enviados a 10 instituições não foram respondidos e em uma, as exigências de tramitação no comitê de ética do próprio serviço inviabilizaram a realização de entrevistas. Desta maneira, o universo do estudo ficou restrito a EO de 12 instituições de saúde privadas. Porém, não foram incluídas EO de três instituições, pois duas delas fazem parte da mesma rede hospitalar e em outra a entrevista foi cancelada por contratempo ocorrido com a pesquisadora, não sendo possível conciliar nova oportunidade para coleta dos dados. Assim, foram realizadas entrevistas com EO de nove instituições diferentes. A Figura 1 mostra o fluxo para seleção das instituições que constituem o universo do estudo. 


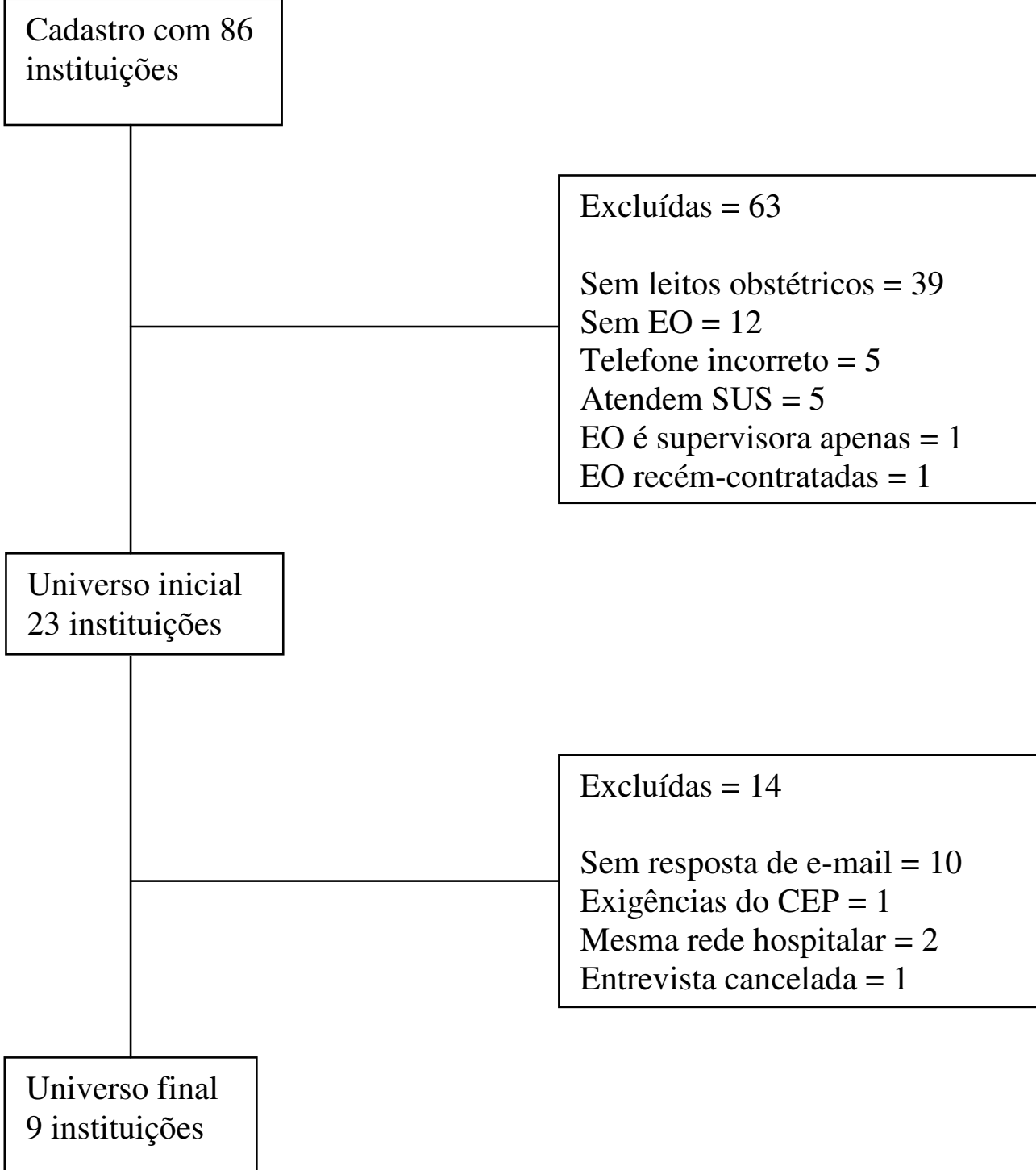

Figura 1. Fluxograma da seleção das instituições do estudo. São Paulo, 2007-2008.

Ao todo, foram realizadas entrevistas com $15 \mathrm{EO}$, que constituem a população do estudo. Utilizou-se como critério de inclusão a disponibilidade da EO para participar e o tempo mínimo de um ano de atuação na instituição. O número de EO entrevistadas em cada instituição é apresentado do Quadro 1. As EO foram identificadas pelos números de 1 a 15 e as instituições de saúde foram codificadas pelas letras de A a I. 
Quadro 1. Número da EO entrevistada e código da instituição de saúde. São Paulo, 2007-2008.

\begin{tabular}{|c|c|}
\hline Enfermeira obstétrica & Código da instituição \\
\hline EO1 & A \\
\hline EO2 & B \\
\hline EO3 & C \\
\hline EO4 & C \\
\hline EO5 & A \\
\hline EO6 & A \\
\hline EO7 & D \\
\hline EO8 & D \\
\hline EO9 & A \\
\hline EO10 & E \\
\hline EO11 & F \\
\hline EO12 & G \\
\hline EO13 & F \\
\hline EO14 & H \\
\hline EO15 & I \\
\hline
\end{tabular}

\subsection{Coleta de dados}

Os dados foram coletados por meio de entrevista semi-estruturada, realizada com cada uma das EO, informando-as sobre o objetivo, a metodologia e o uso de gravador. Doze entrevistas foram realizadas no local de trabalho da EO e três ocorreram na residência da EO. As entrevistas foram feitas entre fevereiro $2007 \mathrm{e}$ fevereiro de 2008.

Para cada profissional, foi solicitado um relato verbal, descrevendo sua atividade cotidiana na assistência ao trabalho de parto e parto, considerando aspectos que representam o trabalho colaborativo entre enfermeiras e médicos, a atuação autônoma da enfermeira obstétrica ou a restrição desta autonomia. Depois de 
concluída a narrativa, foram feitas perguntas relativas à composição e coordenação da equipe de obstétrica e a sua percepção profissional dentro da equipe. (Anexo A). As entrevistas tiveram uma duração média de 30 minutos.

\subsection{Análise dos dados}

As entrevistas gravadas foram inteiramente transcritas, para se proceder a leitura integral das narrativas e das respostas às perguntas do roteiro, com a finalidade de para melhor compreender o conteúdo de cada uma. Por meio de um processo contínuo, buscamos organizar os dados em temas, realizando a análise de conteúdo.

A análise de conteúdo é um método que vem sendo amplamente aplicado em pesquisas, geralmente em trabalhos que envolvem avaliações e interpretações de dados. Seus resultados são baseados em elementos textuais de um contexto discursivo. Trata-se de um método de análise que trabalha com a categorização de dados verbais, através da classificação, codificação e organização do conteúdo obtido em temas. $^{47}$

As etapas seguidas na análise podem ser denominadas de pré-análise, ordenação dos temas e interpretação.

A primeira etapa - pré-análise - consistiu na transcrição e leitura inicial do material transcrito. Na etapa seguinte, foi realizada a exploração do material através de leitura exaustiva, delimitando e codificando as falas e ordenando os dados nos temas. Nessa etapa, o conteúdo abordado na entrevista foi identificado e definido nos seguintes temas: Autonomia; Confiança e cumplicidade: principais facilitadores da autonomia; Outros aspectos facilitadores da autonomia; Dificuldades para a autonomia; Facilitadores do trabalho colaborativo; Barreiras para o trabalho colaborativo; Percepção da inserção da enfermeira obstétrica na equipe; Composição e coordenação da equipe de assistência ao parto; Reflexões sobre a atuação da enfermeira obstétrica nas instituições de saúde privadas. Por fim, foi realizada a interpretação dos dados, a partir das informações obtidas e de explicações em torno da dimensão teórica. Para tanto, os conceitos de autonomia profissional e 
trabalho colaborativo, apresentados na Introdução, foram incorporados como referencial para orientar a análise.

Os trechos de cada fala transcrita foram identificados utilizando-se as letras EO e os números de 1 a 15, segundo a seqüência cronológica de cada entrevista. As letras de A a I foram utilizadas para representar a instituição de saúde onde a EO atua. Assim, EO1-A indica que foi a primeira EO entrevistada e que essa EO atua a instituição A (Quadro 1). Os trechos das entrevistas foram adotados para ilustrar, em cada tema, o conteúdo analisado.

\subsection{Aspectos éticos}

Este estudo integra projeto relativo à mesma temática, anteriormente submetido e aprovado pelo Comitê de Ética em Pesquisa da Escola de Enfermagem da USP (Anexo B).

Todas as EO participaram voluntariamente, mediante assinatura do Termo de Consentimento Livre e Esclarecido (Anexo C). Foram fornecidos os esclarecimentos requeridos, garantindo a liberdade de não participar do estudo e assegurado o anonimato na apresentação dos resultados.

Para o desenvolvimento do estudo, foram seguidas as diretrizes e normas que regulamentam as pesquisas que envolvem seres humanos, aprovados pelo Conselho Nacional de Saúde - Resolução 196/96 (Brasil, 1997). 


\section{RESULTADOS E DISCUSSÃO}

Os resultados deste estudo são apresentados nos seguintes itens: 4.1 Caracterização das instituições de saúde e das enfermeiras obstétricas, considerando as características das instituições de saúde em que as enfermeiras obstétricas atuavam; 4.2 Atuação da enfermeira obstétrica na assistência ao parto e inserção na equipe obstétrica, considerando os dados qualitativos obtidos na sistematização das entrevistas. A discussão dos resultados é apresentada juntamente com a exposição dos dados, seguida das Considerações finais.

4.1 Caracterização das instituições de saúde e das enfermeiras obstétricas

Foram entrevistadas 15 enfermeiras obstétrica (EO), que atuavam em nove instituições: duas são exclusivamente maternidades de grande porte, com média mensal de 600 partos; duas são hospitais gerais de grande porte, em cujas maternidades são realizados mais de 200 partos por mês; quatro são hospitais gerais de médio porte, com média de 100 partos por mês; uma instituição é um hospital geral de pequeno porte, em cuja maternidade são realizados por mês uma média de 30 partos.

No centro obstétrico dos hospitais e maternidades de grande porte trabalham duas a três EO nos períodos da manhã e tarde e duas EO à noite e nos finais de semana. Nas outras instituições, trabalham duas EO no período da manhã e uma à tarde e à noite. Sete das EO entrevistadas atuavam exclusivamente no centro obstétrico e seis atuavam também nas unidades de internação da maternidade. Duas EO exerciam a função de supervisoras de enfermagem no centro obstétrico e unidades de internação da maternidade e foram incluídas no estudo porque atuavam como EO na equipe, quando necessário. 
Cinco instituições tem "corpo clínico aberto", pois aceitam que médicos externos, sem vínculo empregatício com a instituição, realizem a internação e o parto das clientes particulares de seu consultório. Possuem médicos de plantão apenas para realizar atendimentos de emergência. Nas outras quatro instituições, trabalham apenas os médicos plantonistas; não há a presença de médicos externos.

Conforme descrito no Método, as EO foram identificadas pelo código EO1, EO2 e assim sucessivamente, seguido na letra de A a I, referente à instituição onde atuava. (Quadro 2).

Quadro 2. Caracterização das EO entrevistadas. São Paulo, 2007-2008.

\begin{tabular}{|c|c|c|c|}
\hline $\begin{array}{l}\text { Enfermeira } \\
\text { obstétrica }\end{array}$ & $\begin{array}{c}\text { Tempo de } \\
\text { formada (anos) }\end{array}$ & $\begin{array}{c}\text { Tempo de trabalho } \\
\text { na instituição (anos) }\end{array}$ & $\begin{array}{c}\text { Instituição onde } \\
\text { trabalha }\end{array}$ \\
\hline EO1 & 10 & 5 & A \\
\hline $\mathrm{EO} 2$ & 12 & 1 & B \\
\hline EO3 & 23 & 6 & $\mathrm{C}$ \\
\hline EO4 & 20 & 6 & $\mathrm{C}$ \\
\hline EO5 & 7 & 1,5 & A \\
\hline EO6 & 13 & 5 & A \\
\hline EO7 & 5 & 3 & $\mathrm{D}$ \\
\hline EO8 & 8 & 6 & $\mathrm{D}$ \\
\hline EO9 & 16 & 6 & A \\
\hline EO10 & 5 & 1,5 & $\mathrm{E}$ \\
\hline EO11 & 23 & 6 & $\mathrm{~F}$ \\
\hline EO12 & 9 & 1,7 & $\mathrm{~F}$ \\
\hline EO13 & 5 & 2 & $\mathrm{G}$ \\
\hline EO14 & 23 & 1 & $\mathrm{H}$ \\
\hline EO15 & 5 & 3 & I \\
\hline Média & 12,2 & 3,6 & \\
\hline
\end{tabular}


4.2 Atuação da enfermeira obstétrica na assistência ao parto e inserção na equipe obstétrica

Nesse item são apresentados os temas: Autonomia; Confiança $e$ cumplicidade: principais facilitadores da autonomia; Outros aspectos facilitadores da autonomia; Dificuldades para a autonomia; Facilitadores do trabalho colaborativo; Barreiras para o trabalho colaborativo; Percepção da inserção da enfermeira obstétrica na equipe; Composição e coordenação da equipe de assistência ao parto; Reflexões sobre a atuação da enfermeira obstétrica nas instituições de saúde privadas. Esses temas são discutidos considerando os conceitos de autonomia e trabalho colaborativo, apresentados na Introdução, incorporando-se os seguintes elementos, presentes na literatura relativa à temática: conhecimento teórico e prático; reconhecimento do ambiente de atuação; competências para fazer escolhas; capacidade de agir, decidir; responsabilidade na tomada de decisões; reconhecimento e valor individual e profissional de cada parte; comunicação, diálogo verdadeiro, ouvir ativo; habilidade para negociar e trabalhar em conjunto. ${ }^{38,43}$

\subsubsection{Autonomia}

Apesar de esforços das políticas de saúde empreendidas na última década, em âmbito nacional (MS e ANS) e internacional (OM e ICM), no sentido de reconhecer a EO como o profissional indicado para prestar assistência à mulher no ciclo grávidopuerperal de baixo risco, essa diretriz ainda não é seguida pelas instituições de saúde privadas. Nas instituições do SUS, ao contrário, as EO têm uma inserção reconhecida e o seu trabalho ocorre com mais autonomia e em colaboração com os médicos. ${ }^{32,35}$ No entanto, a organização da assistência nas instituições privadas nem sempre é compatível com as definições das políticas de saúde oficiais.

As EO que trabalham nas instituições que recebem médicos externos cadastrados referem, conforme os relatos, uma autonomia limitada. A sua atividade realizada com autonomia acontece principalmente durante a triagem das gestantes e 
parturientes que chegam à maternidade. É um momento em que a EO pode exercer a sua função com os conhecimentos que possui como, por exemplo, avaliar em qual estágio do trabalho de parto a parturiente se encontra e fazer avaliação das queixas clínicas e do bem-estar fetal por meio da cardiotocografia. Na triagem, a EO atende diretamente a mulher, ouve suas queixas e as perguntas que ela faz, tem a liberdade de tomar condutas, sem a presença de outro profissional para controlar ou conduzir a sua atividade. Nesse primeiro contato, a EO faz um exame minucioso, colhe as informações da mulher e toma as providências que acredita serem pertinentes para a situação e, em seguida, entra em contato telefônico com o médico responsável.

Essa autonomia é reconhecida pelas EO muito mais como uma "liberdade para atuar" do que como autonomia, propriamente dita, que é definida como "faculdade de decidir-se por si mesmo". ${ }^{37}$ Como elas atuam desta forma apenas na triagem das mulheres pode-se considerar que a autonomia que dizem possuir é muito restrita, porque dependem da "autorização" médica para dar continuidade aos cuidados.

Alguns autores consideram que o exercício da profissão com autonomia requer três pré-requisitos: competência para trabalhar naquilo que conhece responsabilidade na tomada de decisões; confiança e reconhecimento das suas atribuições profissionais por parte dos médicos e outros profissionais da saúde para atuar com liberdade e, por fim, o mais importante, o apoio tanto da supervisão de enfermagem como também de outras EO. ${ }^{17,36,43,46} \mathrm{O}$ entendimento que as EO manifestam com relação ao reconhecimento da autonomia apóia-se no "senso comum" e, na maioria das situação, não condiz com o significado apresentado na literatura, nem com os preceitos da OMS e do MS para o trabalho da EO. Porém, é possível observar que as $\mathrm{EO}$ reconhecem que têm conhecimento teórico e prático para dar assistência à mulher, mas também têm consciência que para desempenhar as suas atribuições com autonomia precisam ter essas atribuições reconhecidas pela equipe médica.

A minha atribuição aqui é fazer o que eles (médicos) pedem. (EO7-D)

Apesar de usarem o termo autonomia, é possível observar que se referem à situação no momento da triagem, quando podem tomar decisões. Trata-se de uma 
oportunidade em que podem exercer e demonstrar os conhecimentos e o potencial que possuem para prestar assistência às parturientes. É um momento em que podem fazer uso dos seus conhecimentos obstétricos e não dependem da autorização de outros profissionais para atuar e tomar decisões. No entanto, logo em seguida, assim que entram o contato com o médico, passam a executar pequenas tarefas muito aquém das suas habilidades. Quando a EO tem suas competências pouco reconhecidas, torna-se insegura para expandir a sua área de atuação e, em contrapartida, os médicos resistem em consultá-as ou em trabalhar de maneira colaborativa.

Quando ele está longe, você tem uma autonomia de sugerir alguma coisa, ou melhor, você tem uma liberdade de fazer alguma sugestão. Não é uma autonomia. (EO2-B)

O momento que eu tenho mais liberdade aqui é quando eu vou até a triagem. A paciente chega da rua e eu vou tirar os dados dela e vou fazer um exame de toque ou decido se vou fazer uma amnioscopia. Decido o que eu vou fazer, ligo para o médico e falo: olha, está assim. (EO6-A)

A gente tem essa autonomia para ouvir a queixa e, a partir da queixa, tomar uma conduta. Não temos a autonomia para fazer nenhum tipo de medicação, só essa autonomia de examinar e tal, e aí ligamos para o médico e ele dá o parecer dele, a conduta dele. Na própria ficha de internação, já tem as condutas que a gente deve fazer: manter jejum, tricotomia, controle de foco, cardiotoco tal hora. (...) Autonomia, só no sentido de identificar, na triagem. Depende muito da equipe que você trabalha. Ela [a autonomia] não é imparcial, ela sempre depende de quem está junto com você. (EO7-D)

Os cuidados da EO variam para cada paciente, não porque a EO ofereça um cuidado individualizando às necessidades da mulher, mas porque a conduta depende exclusivamente do médico responsável, principalmente nas instituições que aceitam médicos externos, que não se encontram na instituição no momento da internação de sua cliente. Assim, as condutas para a assistência prestada pela EO dependem sempre da orientação e anuência do médico. 


\subsubsection{Confiança e cumplicidade: principais facilitadores da autonomia}

A confiança é um tema que surgiu com muita frequiência nas respostas das EO. Confiança é definida como: "1. Segurança íntima de procedimento; 2. Crédito fé; 3. Segurança e bom conceito que inspiram as pessoas de probidade, talento, discrição."37 A confiança requer tempo para ser construída ao longo do relacionamento profissional e pessoal. Quando as pessoas envolvidas sentem-se seguras quanto às competências e os conhecimentos de cada um, a confiança se dá. Porém nota-se que, mesmo depois de muito tempo de convivência, ainda se fazem necessários o consentimento e as diretrizes do médico nas condutas.

Eu acho que eu me sinto super autônoma e independente, mas a gente precisa colocar o nosso trabalho perante os médicos. Por exemplo: tudo o que a gente faz aqui precisa colocar para o médico, tenho que dar uma satisfação. Até que tem algumas equipes que a gente tem mais intimidade, mas o certo, principalmente numa instituição particular, é [que] até [para pedir] uma glicose a gente precisa ligar para o médico antes, para ver se ele autoriza. Eu tenho liberdade, eles têm plena confiança na gente e têm o reconhecimento pela minha capacidade profissional. É claro que a gente tem mais intimidade com umas equipes que com outras." (EO4-C)

Em algumas situações, quando o médico e a EO já se conhecem e se estabeleceu uma relação de confiança, ela sente que pode negociar e sugerir condutas. Mas, na maioria dos casos, os procedimentos e condutas terapêuticas no trabalho de parto são decididos unicamente pelos médicos. Segundo as EO, cada médico tem a sua maneira de trabalhar, que elas conhecem bem, por isso dizem que possuem "autonomia" para atuar. No entanto, é uma "autonomia" para fazer aquilo que eles querem que seja feito enquanto não chegam ao hospital.

Quando as EO não conhecem o médico, sentem-se inseguras para tomar atitudes, mesmo aquelas básicas, como encaminhar a parturiente ao chuveiro ou estimular a deambulação. A "autonomia" da EO, portanto, depende de cada médico, e não pode ser considerada uma autonomia; ela não pode ser EO e atuar como tal em 
todas as situações, pois sempre necessita da autorização do médico para isso. Esta necessidade de autorização limita suas atitudes, tornando o seu trabalho "pobre e sem destaque".

Eu acho que tenho sim [autonomia]. Posso ligar [telefonar] ou sugerir condutas, falar o que estou fazendo ou que vou fazer. Eu acho que a gente faz, sabe o que está fazendo. Essa atitude é aceita pelos médicos, de um modo geral. Porque, por exemplo, não é tudo que a gente pode tomar a iniciativa de fazer, como por exemplo ligar um soro, romper uma bolsa. Às vezes, a paciente está com o cardiotoco e a gente quer tirar, para ela andar ou levar para o chuveiro, não é todo mundo que é assim, depende da equipe do médico você não pode oferecer tanta coisa, você tem que sentir a situação, para aí poder investir mais ou investir menos. (EO9-A)

Com alguns médicos tenho autonomia. Tem algumas equipes que você não consegue fazer absolutamente nada, a paciente chega e você não tem autonomia nem para tocar a paciente. Com outras equipes que você conseguiu desenvolver alguma confiança maior, uma interação melhor, acaba tendo uma autonomia maior, porque o médico acaba confiando mais. Então, vai muito da sua interação com a equipe médica. Mas eu acho que autonomia a gente não tem praticamente nenhuma. E aí você até sugere, mas ele acha que não, então é não, e você não tem autonomia. (EO13-G)

O vínculo de confiança com os médicos é estabelecido no trabalho do dia-adia. Quando a EO é "autorizada" pelos médicos para trabalhar em conjunto, cooperando com a assistência às parturientes, tem suas funções valorizadas e respeitadas, se sente realizada profissionalmente e a assistência ganha qualidade. Quando o trabalho dela é pouco reconhecido, sente-se frustrada, executa as condutas impostas e as atividades burocráticas com pouco interesse.

Sinto-me muito bem. Isso aqui é como a minha casa. Sintome à vontade. As pessoas, médicos e enfermeiras, me conhecem, sabem o meu jeito de trabalhar, confiam em mim e, é claro, eu já trabalho aqui há muito tempo. Eu já vi muito isso de fazer uma onda com a família e desdizer o que você falou. É muito raro, mas às vezes acontece. A maioria respeita, e tem aqueles que reconhecem e que falam: 'ai, que bom que você está aî'. Adoro ouvir isto. Aqui, no pré-parto é 
melhor. Lá no centro obstétrico, não. Você é ótima, mas quando não tem sala você é uma porcaria. $O$ fato de não ter a sala, você já é uma droga. (EO3-C)

Para a instituição, sinto que a gente é mais uma colaboradora, que tem um conhecimento diferenciado. A gente sabe mais até que eles, porque agente faz muito, vê muito, tem conhecimento, mas não tem nenhum destaque. A gente vai crescendo e vai fazendo, mas não é vista pela instituição, não é reconhecida. Acho que a satisfação em trabalhar em uma instituição particular, quando falo com outras colegas também gira muito em torno disso. (EO8-D).

Sinto-me com autonomia, segura, podendo chamar a hora que eu quiser, podendo dividir e discutir o caso. Quando não tem essa liberdade, fica complicado, me sinto mal, impotente, não estou servindo para nada aqui. Tem os dois lados: tem profissionais e profissionais. Um dia me sinto ótima, porque veio uma equipe que eu consigo me inserir, outro plantão vem uma equipe que eu não consigo me inserir. Então, depende de quem está trabalhando comigo, especialmente a equipe médica. (EO15-I)

Quando o médico conhece as atribuições da EO e tem oportunidade de observar seu trabalho e o produto dele, passa a confiar na sua competência. Essa confiança é a segurança para a EO agir com maior autonomia. Para tanto, é necessário que a EO possua conhecimentos teóricos e habilidades práticas, para ser reconhecida e valorizada na profissão que desempenha. As EO que trabalham há mais tempo na instituição conhecem melhor os médicos que mais freqüentemente internam gestantes e parturientes e, por isso, estão habituadas às suas condutas, o que facilita o seu trabalho. Mesmo assim, como ainda são poucos os médicos que realizam partos normais em suas clientes particulares - a prevalência de partos cirúrgicos nas maternidades particulares é alta -, as atribuições das EO ficam limitadas aos procedimentos de internação da gestante para cirurgia. $\mathrm{O}$ trabalho de parto, nas instituições privadas, é acompanhado pelos médicos das equipes responsáveis e as EO ficam na retaguarda para ajudar no que for preciso.

(...) não com todos os profissionais, mas alguns profissionais que antes nunca deixavam a gente acompanhar um trabalho de parto. Hoje têm uma ou duas médicas que deixam até com a gente. (EO6-A) 
Acho que o que facilita a nossa autonomia é o trabalho com os obstetras mesmo, a credibilidade deles, a abertura deles para a nossa função. (EO8-D)

Percebo que o pessoal confia. Os obstetras, anestesistas confiam no que a gente faz e no que a gente fala. Então, dá uma autonomia melhor, a gente se sente melhor assim. Acho que ajuda quando uma pessoa chega no setor para fazer um parto e conhece a equipe; para a gente, como obstetriz favorece. (EO9-A)

A confiança é construída, eu acho que principalmente com o tempo e com o seu trabalho diário. $\mathrm{Na}$ verdade, é um trabalho de formiguinha, você vai atendendo as pacientes de determinado médico, vai mostrando a ele o conhecimento, que você sabe o que você está falando. (...) A própria enfermeira mostrar que ela é importante. Muitas vezes, a enfermeira desvaloriza o seu trabalho. Para sermos respeitadas, precisamos valorizar o nosso trabalho $e$, efetivamente, colocar em prática aquilo que a gente aprendeu Eu penso que o meu trabalho é muito importante, porque se eu não estivesse aqui uma série de coisas não aconteceriam. (EO13-G)

\subsubsection{Outros aspectos facilitadores da autonomia}

A facilidade para desempenhar as suas tarefas com autonomia ocorre principalmente nas instituições onde os médicos são funcionários e trabalham em regime de plantões. Ela é reforçada por meio do contato e do relacionamento profissional que as EO têm com os médicos plantonistas e do conhecimento que eles têm quanto às atribuições e habilidades da EO. A autonomia para trabalhar é conquistada, na medida em que a EO tem a oportunidade para mostrar o seu conhecimento com segurança. Quando trabalham juntos, aprendem a confiar uns nos outros, porque se conhecem, e quando surge a necessidade de discutir alguma conduta, estão sempre presentes para dar suporte. A facilidade para desempenhar as suas tarefas com autonomia é reforçada, porque o relacionamento profissional acontece com médicos plantonistas, que já são conhecidos. Eles trabalham dentro da instituição, como plantonistas, e estão sempre presentes no momento em que elas 
necessitam discutir algum caso. Quando os médicos não podem estar presentes, as EO realizam os partos com a anuência destes e da instituição.

No entanto, a intenção tanto dos médicos como das EO para trabalharem em conjunto é fundamental para facilitar o trabalho da EO com autonomia:

O que facilita é como cada médico traz [vê] o papel da enfermeira para ele. Como que ele vê a importância da enfermeira obstétrica. Aquele que respeita o trabalho, que confia que valoriza o papel, que sabe o quanto que a gente é preparada para isso. Quando ele reconhece o papel da enfermeira, você tem autonomia. É, claro, que se você faz as coisas dentro do que se espera, se você mostrar seriedade e responsabilidade naquilo que você faz, você até conquista a confiança daqueles que não confiavam muito. Mas aquele que não tem isto dentro dele, não sei se a sua seriedade e o que você faz vai mudar o que ele pensa. (EO7-D)

Eu acho que a autoconfiança é o principal e o conhecimento também; saber o que está fazendo, mostrar o porquê que está fazendo, porque que você gostaria que aquilo fosse feito, ou seja, comunicação. (EO10-E)

O querer! Hoje é o querer, porque as portas estão abertas, a equipe é muito receptiva, porque a equipe médica da casa já sabe o valor da enfermeira obstétrica. Eles querem e ajudam, e estão sedentos por ajuda. (EO11-F)

O conhecimento! Então eu acho que o que norteia isso é o fato de ele saber que aquela pessoa conhece muito que faz. (EO14-H)

O que facilita é o conhecimento, conhecimento da enfermeira obstetra. Isso é a base de tudo. Não é ser legal, gente boa, comunicativa, não! Tem que ver que dá para confiar. Ter um plantonista aqui no hospital, isso facilita muito o trabalho da gente. (EO15-I) 


\subsubsection{Dificuldades para a autonomia}

Quando as parturientes chegam às instituições que têm "corpo clínico aberto", os médicos, freqüentemente, estão fazendo atendimentos em seus consultórios particulares ou em outros locais e, por isso, deixam as condutas muito bem estabelecidas para as EO. Nessas situações, o parto deve acontecer em um horário que seja compatível com as outras atividades do médico. Atender a essas exigências restringe a autonomia da EO, na medida em que ela fica impossibilitada de conduzir os cuidados no trabalho de parto, acompanhar sua evolução fisiológica ou tomar alguma iniciativa pertinente.

Além disso, o elevado índice de cesáreas eletivas reduz a liberdade de atuação da EO na atenção ao trabalho de parto. Nesses casos, as suas atribuições são apenas de internar a gestante e prestar os primeiros cuidados ao recém-nascido, juntamente com o médico neonatologista.

Ah sim!!! É uma autonomia dentro de uma regra porque as vezes há restrições quando por exemplo o médico vai demorar para chegar ele mesmo avisa "olha não posso ir agora só vou no final da tarde”, então você toma certo cuidado. Mas estas pacientes que internam o trabalho é bem mais "light", não tem aquele controle porque vai para a cesária mesmo então não tem muito que fazer. (...) Tem médico que você sente que tem mais a abertura e aí vai numa boa, mas têm alguns extremamente fechados e, às vezes, eles vêm em dois médicos e aí fico mesmo assim, à disposição do bebê. A paciente é particular, ela é deles. (EO2-B)

[Uma barreira seriam] os egos inflados. (...) A equipe importante são os médicos. Acredito que se eles permitissem, a instituição também permitiria, mas do jeito que é hoje, no esquema que é hoje, não! São eles que comandam. Aqui no hospital, quem mandam são os médicos, eles fazem tudo. (EO3-C)

A gente sabe que o paciente particular é bem complexo ele pede o médico dele, ele quer o médico dele presente, ele não quer que fique o enfermeiro... Primeiro tem aquela questão da relação paciente e médico, o que, que acontece: eu não tenho aquele relacionamento de uma gravidez inteira, e isso é importante na gravidez, eu estive grávida até a pouco 
tempo, e isso é importante você está com a pessoa que você confia que você deu não só a sua vida mas a do seu filho para ela cuidar e zelar. Então nem é tanto pela competência enfim, mas por essa questão de ter esse laço com aquele profissional, e com as enfermeiras daqui você não tem porque gente chegou agora. Mas se a equipe tivesse mais um pouco de confiança e tal não se desgastaria tanto também, agente poderia tocar este trabalho de parto um pouco, talvez. não até oito centímetros, mas não precisa chegar aqui com dois centímetros, agente tem competência para isso. Aí agente teria um relacionamento melhor e eu uma também autonomia melhor. (EO6-A)

Como é um hospital particular, todas as pacientes têm seus médicos pré-natalistas, 99,9\%, é muito. Então, nós é que avaliamos a paciente e aí ligamos, entramos em contato com o obstetra da paciente, e ele vai ditar as condutas. (...) A enfermeira de um hospital privado, como eu converso com minhas amigas, me parece que é muito limitada, muito mesmo. Então, a gente faz conforme o médico diz. Autonomia [risos] não tem muito. A gente não tem autonomia nem para romper uma bolsa, aquela coisa básica. Focando, acompanhando, a gente liga conforme está a evolução, mas é ele que determina a conduta. (EO8-D)

A planta física das instituições, com serviços em andares diferentes, é uma barreira para a EO desenvolver a sua atividade: em algumas instituições, a triagem, o centro obstétrico e a unidade de internação maternidade ficam em andares diferentes. Essa situação exige que a EO se desloque com freqüência, impedindo que permaneça mais tempo junto às clientes, comprometendo a qualidade da sua atuação.

No meu hospital, a planta física é muito difícil. Como somos uma, às vezes duas [EO], para fazer a triagem, assistência no puerpério a e sala de parto, na hora que um trabalho de parto evolui e o doutor determina ou decide descer para o centro cirúrgico, a gente desce junto e aí a outra enfermeira fica com tudo (clínica e maternidade). Não é aquela assistência que a gente gostaria. $O$ dia que este número de partos aumentar, isso não vai dar certo. Não vai dar para manter a qualidade com tudo isso, sendo cada coisa num andar! (EO8-D)

$O$ pré-parto e o centro obstétrico são no terceiro andar e o berçário e maternidade, no quarto andar. Mas a minha sina é o pré-parto e a maternidade, fico o dia inteiro subindo e descendo escada. (EO12-F) 
Numa das instituições, o plantão é compartilhado com uma enfermeira generalista e, quando a EO precisa atender na triagem ou acompanhar uma mulher em trabalho de parto no centro obstétrico em outro andar, a maternidade fica ao encargo dessa enfermeira, que não está qualificada para as funções de EO, como identificar a fase do trabalho de parto, promover o alívio da dor e, no pós-parto, prestar cuidados durante a amamentação. Essa situação causa frustração, porque suas atribuições como EO não se evidenciam, ela não consegue dar a atenção e a assistência que gostaria às mulheres.

Na verdade, a idéia é que nos plantões tenha duas enfermeiras obstétricas e uma clínica. Porém, acontece muito do hospital precisar da enfermeira clínica em outro lugar e a enfermeira obstétrica ficar com tudo. Então, isto me frustra um pouco, porque eu queria estar mais voltada para aquilo que eu sei. É muito importante que as enfermeiras do andar tenham uma sintonia muito boa. (EO7-D)

A autonomia de atuação da EO é menor, principalmente nas maternidades que aceitam os médicos externos. As condutas e orientações médicas para com as clientes particulares permitem pouca abertura para sugestões e discussões de condutas, o que resulta numa barreira para a autonomia da enfermeira.

Você não se sente assim tão à vontade para sugerir. Eu poderia atuar muito melhor, eu poderia mostrar o meu lado de enfermeira obstétrica, a minha competência, o meu conhecimento muito mais, se tivesse liberdade de atuar. Eu sinto que essa liberdade é restrita e bem amarrada mesmo. A gente fica amarrada. (...) Eu acho que tenho pouca liberdade. (EO1-A)

A maioria já vem com uma conduta fechada, já vem com um jeito ' $X$ ' próprio de trabalhar, a sua rotina mesmo. (EO5-A)

As EO não acreditam que possam ter mais espaço para desenvolver o trabalho com maior autonomia, porque o vínculo de confiança que existe entre o médico e a sua cliente particular justifica a atitude de "posse", situação em que somente eles podem conduzir os cuidados. É possível reconhecer essa percepção através da seguinte fala: 
Não vai acontecer esse espaço, mesmo que ele confie no seu trabalho porque a questão é além disso. É um negócio, e como você vai negociar com ele o que não é vantajoso naquele momento? (EO8-D)

Assim, a EO fica à margem do cuidado e da assistência à mulher, desempenhando apenas uma função de dar suporte ao trabalho do médico, quando solicitada.

Na instituição particular tem muito essa coisa do doutor. $O$ doutor tem muita síndrome de Elis Regina, estrela! Eu sou muito importante, todos são importantes, a faxineira é muito importante, é fundamental. Então, na instituição particular isto é muito mais forte, ele tem o DR e por isto ele pode ou ela pode. Fica difícil de exercer a sua profissão com autonomia ou em colaboração, porque esse poder que ele tem acaba dificultando bastante. (EO1-A)

Acho que antes de qualquer coisa, a cabeça do médico. Ele não vê a obstetriz como um braço direito, ele a vê como ladra: ela esta roubando a minha função. É assim que eu vejo. Tem médico que não gosta que a gente toque a paciente deles. Nós estudamos, somos habilitadas para isto. Eu entendo assim, eu acho que deveria fazer um trabalho de conscientização dos médicos para eles entenderem qual a função da EO, e que eles mesmos não sabem. Se eles tivessem um pouco mais de conhecimento e entendessem mais qual a nossa função, não teria essa coisa de posse da paciente. Uma coisa bem arcaica; ainda existe isso. (...) Porque nós somos enfermeiras extremamente competentes. Eu acho que nós, muitas vezes, não fazemos nada porque a gente se sente acuada, a gente se sente assim como se as equipes não confiassem na gente. E, aí a gente não consegue atuar muito. Eu acho que essa posse que o obstetra tem em relação à paciente dele impede que a gente atue também, porque ele fica tão zeloso, que ele não deixa a gente levar a coisa mais tranqüila. Depois que interna, só vêm ordens, não vem uma liberdade. A minha atribuição aqui é fazer o que eles me pedem. (EO5-A)

Na maioria das vezes, chega a equipe inteira. Eles decidem, resolvem, eles que tocam. A gente não toca mais, a gente não sabe qual a evolução daquela paciente. A gente só sabe por aquilo que eles nos falam. Então, eu me sinto bem excluída do trabalho de parto. Deixam 'cozinhando o galo' $e$ aí concluem: 'ah, não está evoluindo'. Aí, indicam a cesárea. (...) Eu sou eu sempre tive isso, eu sou os dedinhos e os olhinhos quem vai decidir não sou eu. A minha atribuição aqui é fazer o que eles me pedem. (EO6-A) 


\subsubsection{Facilitadores do trabalho colaborativo}

O trabalho colaborativo acontece quando há confiança entre os profissionais e interesse das EO em conhecer os procedimentos e ganhar experiência. É importante que a EO tenha boa habilidade para se comunicar de uma maneira clara, para expressar os seus conhecimentos, discutir, dialogar, perguntar e sugerir condutas. Fica evidente que a cooperação entre os profissionais é facilitada quando trabalham próximos e se conhecem há algum tempo. Assim que os dois profissionais se conhecem melhor, tanto na forma de conduzir o seu trabalho como também quanto às características pessoais, a cooperação é facilitada. $\mathrm{O}$ relacionamento colaborativo com as enfermeiras acontece quando há uma afinidade pessoal e profissional. $\mathrm{O}$ estudo de Payne ${ }^{18}$ aponta que quando há envolvimento das EO com os médicos em uma atitude colaborativa na atenção às mulheres, este cuidado ganha qualidade porque a assistência torna-se complementar.

Acho que facilitaria na hora que ele conhece você, que ele conhece o seu trabalho. Assim, por exemplo, ontem mesmo teve um médico que disse: 'obrigado pela ajuda!' É uma coisa rara. Olha só, um obrigado. (EO2-B)

Não só conhecer o médico, mas conhecer a paciente que você está atendendo, conhecer a técnica, conhecer tudo. Tem que ter um conhecimento de tudo e você estar confiante daquilo que você vai fazer e está fazendo. Quer queira quer não, são duas vidas que você está cuidando: a mãe e o bebê. Tem que ter conhecimento de tudo, inclusive do funcionamento do hospital. (EO1O-E)

A confiança e o interesse. Sem interesse não dá! Então, a gente tem que correr atrás, buscar as informações. É o movimento mesmo, se você se interessar, você consegue. Ela precisa perguntar, conversar com o plantonista, explicar, $e$ adquirir experiência. (EO11-F)

Mas, a partir do momento que eles começam a conhecer, eles começam a ver o resultado e colaboram, confiam também. (EO12-F) 
Quando a equipe de enfermagem trabalha mais próxima dos médicos, ocorre a colaboração e a enfermeira ganha autonomia para realizar as tarefas, porque tem a confiança dos médicos. Quando você tem uma equipe médica solidária $e$ confiante, você tem muito mais segurança para agir independente. Lógico que eu já conheço qual é conduta daquele médico, então eu sei até onde eu posso ir. (EO14-H)

Acho que tem muito que ver com a afinidade. As enfermeiras têm muito disso. A afinidade conta muito; conhecer a outra pessoa, conhecer o trabalho, o conhecimento que ela tem. (EO15-I)

\subsubsection{Barreiras para o trabalho colaborativo}

O trabalho colaborativo com as equipes médicas nem sempre acontece, porque depende também da vontade dos médicos de se aproximarem das EO, para favorecer a qualidade do atendimento. As EO conseguem sugerir condutas, por vezes timidamente, e com receio de uma resposta não muito cordial, dificultando a comunicação e a inter-relação dos profissionais.

A gente acaba tendo muito medo de falar, eu não estou falando que só eles têm culpa, a gente acaba ficando com tanta restrição de falar alguma coisa. Dependendo da equipe do médico, você não pode oferecer tanta coisa, você tem que sentir a situação para aí poder investir mais ou investir menos. (...) Tem sim. Depende da equipe, da equipe e do médico. Tem médico que a gente liga e passa a avaliação para ele e ele diz: "o que você me sugere?" (EO5-A)

Hoje dá para conversar, eles têm bastante confiança no que eu faço, existe uma colaboração... Alguns colaboram mais, outros nem tanto, mas no começo foi difícil. (EO10-E)

É possível perceber que a colaboração com o trabalho do médico é reconhecida quando a enfermeira é obediente e executa com presteza as condutas determinadas por ele. 
A colaboração dá muito certo quando o que você faz está dando certo, está de acordo com o que ele espera. Se der errado, para aquele que não valoriza a enfermeira, é porque a enfermeira não fez direito. Se der certo é porque eu (o médico) prescrevi, por isto deu certo. Para aquele que te valoriza, sempre vai ter esta sintonia. (EO7-D)

A tônica em relação ao trabalho colaborativo com os obstetras é de que não há muita abertura para o diálogo e a colaboração. A dificuldade que as EO encontram para trabalhar em cooperação e colaboração com os médicos se deve ao fato de as mulheres serem clientes da clínica particular dos médicos. As condutas são preestabelecidas, com um acordo prévio entre as clientes e o médico quanto à via de parto, que em geral é a via cirúrgica. Esse ambiente impede qualquer abertura para a sugestão ou discussão de procedimentos. A comunicação entre EO e médicos em muitas ocasiões tem uma única direção, que é do médico para com a EO.

Nossa, eu acho que é difícil. É porque a paciente pertence ao profissional responsável por ela. Então, você tem que respeitar as condutas que são dele. A colaboração depende muito do profissional, depende mais da pessoa. Se eu fosse colocar, é mais para não que para sim. Existe muito pouco, muito pouco. Na maioria das situações, a conduta é do profissional e não se discute. Não há nenhuma troca. Raramente, você avalia uma situação. 'Eu quero $X$ ', e aí você não tem margem para discutir. Isso é o mais comum, é o mais comum. (EO2-B)

É todo mundo trabalhar junto, sabe? Que é uma coisa que não acontece em nenhum lugar, que é a gente cuidar da paciente como um todo, as opiniões andarem paralelas. Isto não ocorre. É uma coisa que também a gente acaba se acostumando bastante e isso para mim é uma frustração. (EO5-A)

Nós somos enfermeiras extremamente competentes. Eu acho que nós muitas vezes não fazemos nada porque a gente se sente acuada, a gente se sente assim, como se as equipes não confiassem na gente, e aí a gente não consegue atuar muito. Eu acho que essa posse que o obstetra tem em relação à paciente dele impede que a gente atue também porque ele fica tão zeloso que ele não deixa a gente levar a coisa mais tranqüila. Depois que interna, só vêm ordens, não vem uma liberdade. A minha atribuição aqui é fazer o que eles me pedem. (EO6-A) 
A dificuldade apontada para o diálogo entre os profissionais é que, em algumas situações, a colaboração esbarra na arrogância do médico em não querer reconhecer que está errado ou que a sugestão da EO pode ser uma boa idéia. A relação hierárquica que existe entre médicos e EO impede a cooperação entre os profissionais, gerando um desânimo das EO para discutir ou sugerir alguma conduta e reforça vazios nos cuidados às parturientes e a invisibilidade do trabalho prestado.

Não há uma conversa madura. Fica sempre assim: eu não vou falar por causa disso, eu não vou falar por causa daquilo Se houvesse essa conversa, ajudaria o seu desempenho profissional. Então, a colaboração tem muito que andar com alguns médicos. Não existe a troca, falta muito. (EO1-A)

Essa colaboração não existe, entre você, como enfermeira obstétrica, e o médico obstetra, de você sugerir, enfim, participar um pouco mais no trabalho de parto. Não são todos, mas a maioria é assim. A abertura é muito pouca: sou eu, médico, eu é que mando, eu que faço e aconteço. E então, é muito difícil essa troca entre a enfermeira e o médico obstetra, e isso eu acho que é uma característica do hospital particular. O trabalho colaborativo? Sim, é pessoal. (EO6-A)

Tem algumas coisas que a gente também não discute, por mais que eu ache que não dá. Dependendo do profissional, a gente conversa, mas têm alguns que não dá. Alguns colaboram mais, outros, nem tanto. (EO10-E)

Eu acho que sim, quando você consegue construir esta relação de confiança e de respeito. Às vezes, falta um pouco de respeito. Eu acho que não é por aí que funciona. Mas, quando você consegue construir esta relação de respeito e coleguismo mesmo, você consegue fazer um trabalho legal. Não é fácil. Têm médicos, nossa! que são excelentes, que trabalham muito junto com a enfermagem e valorizam muito o trabalho da enfermagem. Mas a gente percebe que têm alguns que parece que tiveram uma cadeira na faculdade para aprender a ser Deus, e enfermeira que teve uma disciplina na faculdade para aprender a ser bem submissa, entendeu? Acho que é cultural. (EO13-G)

A divergência de pensamento, de conduta, isso atrapalha muito, dificulta. Conduta errada, não está certo, não está correto, e você está limitada, você não vai discutir conduta médica. Então, às vezes, essa colaboração na equipe não funciona bem por um orgulho; mas depende do plantonista. (EO15-I) 
Outra dificuldade apontada pelas EO é a falta de cooperação entre as enfermeiras. Existe um reconhecimento por parte das EO de que a comunicação é uma dificuldade da enfermagem, como um todo. As enfermeiras entre si não discutem os entraves que estão tendo em alguma situação, ou sugestões para facilitar determinada circunstância. $\mathrm{O}$ desconhecimento das responsabilidades e da diferença das condições de trabalho de cada setor, como berçário, maternidade e centro obstétrico, tornam a colaboração difícil e o relacionamento profissional pouco solidário. Através da comunicação, seria possível a aceitação mútua dos profissionais, que poderia resultar em uma sensação de ser co-responsável, caracterizando assim o trabalho colaborativo. ${ }^{46}$ A colaboração é possível apenas quando há comunicação clara e efetiva entre os profissionais, quando o respeito e a confiança são expressos, mas exige das pessoas uma negociação construtiva para que os problemas apontados por cada um da equipe possam ser solucionadas de maneira criativa. $^{16}$

Então, a gente encontra muito isso na enfermagem. Entre os médicos tem corporativismo, tem coleguismo, e entre a enfermagem falta este corporativismo, falta colaboração, falta coleguismo. Eu acho que as enfermeiras são as primeiras a colocarem outras colegas em uma situação difícil. É claro que não são todas, mas tem as suas exceções. (EO13-G)

Às vezes, o berçário não entende por que eu não quero receber o bebê. A mãe não está bem, está hipotensa. Isso é o alojamento conjunto, tem que estar os dois bem, está escrito lá! Para o Ministério da Saúde, a definição é essa. Com o berçário, é mais complicado. (EO15-I)

Existe a percepção de que os componentes da equipe de enfermagem alimentam certa "rivalidade" e, principalmente, que existe falta de colaboração e cooperação entre eles, desmotivando os questionamentos e as discussões. A cooperação seria possível se houvesse uma comunicação clara e franca. Essa comunicação deveria acontecer com periodicidade para permitir a expressão de cada um a quanto as suas percepções e para criar uma relação de inclusão e aceitação, permitindo um funcionamento efetivo da equipe. ${ }^{46}$ 
Acho que vem bastante da gente mesmo. As enfermeiras não têm muito essa coisa de discutir enquanto equipe. Então, há de se conversar, e não se conversa e não se ouve. As pessoas não ouvem umas as outras e se leva para o lado pessoal e não profissional somente. E então, isso é uma barreira. Não há uma conversa clara. (...) Existem reuniões, mas nelas as pessoas não falam as coisas. Nas reuniões, as pessoas não falam sobre essas questões, não abrem a real. Assim: "olha, acontece isso na sua sessão, vocês fazem isso e isso com a gente e nós fazemos isso e aquilo com vocês”. (...) Faço parte da equipe, mas há um isolamento.(...) Cada um cuida da sua parte. (EO1-A)

Talvez a própria comunicação entre a gente, a vontade, porque, às vezes, o que não está bom para mim, para a colega está. Aí, fica aquele receio de falar e ser mal vista. Acho que isso é uma barreira muito grande. Entre a gente, é a falta de vontade de mudar alguma coisa, de se unir. Acho que é isso. Entre nós, enfermeiras obstetras, não tem essa coesão. Acho que poderiam ser mais em conjunto, algumas decisões. Nós, que estamos na prática e vivenciamos aquilo, vemos as dificuldades, sabemos o que seria melhor. Mas, não tem essa oportunidade de trocar essa informação. (EO8-D)

No entanto, as EO prestam cuidados a um grande número de bebês e mulheres, durante 24 horas por dia, nos sete dias da semana, o que resulta em um atendimento com responsabilidade pragmática, padronizado, sempre com o objetivo de diminuir riscos e danos ao binômio mãe e bebê, de forma eficaz e eficiente. A medicalização da assistência contribui para a restrição da autonomia da EO, que tem a sua prática controlada por políticas institucionais e condutas médicas. O reduzido número de EO nos serviços, o alto índice de partos operatórios e a sobrecarga de atribuições dificultam a permanência com a parturiente por um tempo maior, a fim de oferecer a ela o suporte necessário durante o trabalho de parto ou no puerpério. Seguindo esse modelo de trabalho, a atenção dada às mulheres fica muito distante da ideologia humanizadora do parto. $^{21}$

O número reduzido de EO que trabalham na instituição é considerado uma barreira para o trabalho colaborativo. Em algumas instituições, há apenas uma EO, em cada plantão de 12 horas, para atender no pré-parto, centro obstétrico, maternidade e berçário. Provavelmente esta situação justifica a atitude do médico no momento da internação que é de desacreditar na competência da EO, que não está presente em tempo integral para oferecer assistência à sua cliente. Assim, o médico 
geralmente solicita um acompanhamento do ponto de vista obstétrico que não exige a presença assídua da EO, e após algumas horas de internação sem evolução do trabalho de parto indica a cesariana como via de parto, que é o mais comum.

Você percebe também que você não consegue fazer as funções de enfermeira obstétrica e de doula. Não daria para a gente fazer esse papel, não temos tempo. (...) Deixam "cozinhando o galo" e aí concluem: “ah, não está evoluindo”, e aí indicam a cesárea. (EO6-A)

O médico admite a paciente e já vai colocando alguns senões, como: 'olha o bebê está um pouco alto, olha... sei lá'. Como nós não podemos ficar só no pré-parto, a gente perde esta possibilidade. (EO11-F)

As EO gostariam que as instituições reconhecessem que a presença de mais uma EO poderia fazer diferença na qualidade do trabalho, na assistência às gestantes e puérperas e no funcionamento da maternidade. A falta de EO no quadro de funcionários induz a um trabalho mais burocrático e distante das suas atribuições, o que a impossibilita de manter o foco na assistência obstétrica às parturientes. Essa é uma das situações que, segundo as EO, causa irritação na equipe, reforça a hegemonia médica e é, também, responsável pela invisibilidade do seu trabalho.

São poucas enfermeiras. Você sabe que, quando está corrido aqui, está corrido pra tudo quanto é lado. Então, você termina, às vezes, falando: "tomara que o médico chegue logo para assumir". Porque tem um monte de coisa: avaliar as pacientes, escrever, e se tiver alguma intercorrência, é da sua responsabilidade. E tem enfermeira que não gosta mesmo desta parte do normal e prefere mais que alguém assuma. (EO2-B)

Eu gosto, o problema é o estresse e a correria. Aqui tem muito serviço e pouco profissional. Tinha que ter mais gente. $(\mathrm{EO}-\mathrm{C})$

Acho que sou respeitada, consigo agir como profissional com dignidade, mas é como eu te falei: se eu pudesse trabalhar só aqui no pré-parto, poderia ser melhor como obstetriz de trabalho de parto, na condução de trabalho de parto. Mas como eu tenho essa dupla função aqui e lá (centro obstétrico.), então, acaba deixando um tanto a desejar. Poderia ser um pouco melhor. (EO4-C) 
A nossa presença, independente se é o médico que vai realizar o parto ou não, é de muita importância. Aqui, a importância que o hospital põe na enfermeira obstétrica no parto é a recepção do nenê. Eu não acho, sinceramente, importante. Não acho que tem aquele reconhecimento todo como deveria. (EO7-D)

Como somos uma, às vezes duas para fazer a triagem, assistência no puerpério e a sala de parto, na hora que um trabalho de parto evolui e o doutor determina ou decide descer para o centro cirúrgico, a gente desce junto, e aí a outra enfermeira fica com tudo (clínica e maternidade). Não é aquela assistência que a gente gostaria. O dia que esse número de partos aumentar isso não vai dar certo. (EO8-D)

Eu tampo tantos buracos. Aqui sou um pouco de tudo: sou técnica de enfermagem, sou auxiliar de enfermagem, sou enfermeira, às vezes, sou médica, sou escrituraria. (EO12-F)

No entanto, as EO reconhecem que esta é uma realidade (o número reduzido de EO) nos hospitais privados, onde o médico tem todo o respaldo da instituição. A gerência de enfermagem não consegue, em algumas situações, ser atuante perante a administração da instituição e no relacionamento com a chefia médica. Embora, neste estudo tenham sido entrevistadas apenas duas EO com funções administrativas, essa realidade aparece no discurso das EO, mesmo daquelas que não são exercem a atividade administrativa.

Existe o interesse da enfermagem, mas eu acho que a instituição não dá respaldo apoiando. Muitas vezes, a gente vê que o que conta mesmo é o peso do médico. Quando eles determinam uma regra, vai ser aquilo e pronto, acabou. (EO8-D)

Eu, como chefe, ainda noto que algumas pessoas têm certa dificuldade de perceber que não dá para pegar pela mãozinha, que ela precisa ir só. Isso significa a EO se impor na equipe de uma outra forma, também. Porque esta equipe [auxiliares, técnicos] tem que ver nela um líder e não como alguém que executa tarefas baseadas nas determinações de outra pessoa. Então, as enfermeiras, assim como os técnicos, são os grandes responsáveis para isso dar certo. (EO14-H)

O trabalho da enfermeira com autonomia é tolhido quando não há o reconhecimento do seu trabalho. A posição da instituição, representada pela gerência 
de enfermagem, também tem um papel importante na medida em que deveria apoiar e dar respaldo às atividades da EO. Por isso, as EO ressaltam a importância para que a gerência de enfermagem tenha um contato bem estabelecido com a gerência médica e a administração da instituição para defender os interesses da EO e promover sua valorização da equipe obstétrica.

A chefia de enfermagem com certeza fica do lado do médico!!! Totalmente. Quando tem algum problema aqui o médico vai até a diretoria ou para a gerente ou para a chefia e reclama de qualquer coisa como: atrasou a paciente, atrasou sala, qualquer besteira, qualquer coisa, claro coisas graves também que as vezes podem acontecer. Mas a primeira pessoa que eles escutam é o médico não adianta nem perguntar, você vai lá para ouvir bronca às vezes consegue contar o seu lado da historia mas isto não adianta muito não. Então é complicado, quem tem um marketing pessoal, que é mais amigo não tem nem o que discutir com elas. Então o reconhecimento pelo trabalho mesmo por parte da chefia é pequeno. (EO3-C)

\subsubsection{Percepção da inserção da enfermeira obstétrica na equipe}

As respostas ao questionamento sobre a percepção da EO quanto à sua inserção na equipe foram diversificadas. As EO têm consciência de que são um profissional importante, às vezes recebem elogios dos médicos e têm o seu atendimento valorizado por meio de "feedbacks" positivos das mulheres. Consideram que têm muito trabalho, mas fazem aquilo que gostam. Porém, a sua posição na equipe poderia ser mais apreciada, tanto pelos médicos como pelas enfermeiras. Algumas EO consideram que o modelo assistencial que permeia a filosofia das instituições privadas dificulta a sua atuação, porque esse modelo prioriza as funções médicas.

O próprio modelo assistencial é uma barreira o próprio modelo assistencial impede. O próprio modelo de assistência, o papel dos convênios,o papel da instituição,o papel dos médicos. $O$ próprio modelo da assistência termina é complicado. (EO2-B) 
Eu me sinto bem, porque faço o que gosto, o que eu quero e está indo tudo muito bem. Somos reconhecidas sim, pelo nosso trabalho, como por exemplo: 'muito obrigada, valeu!' Tanto por parte dos médicos, como também por parte das pacientes. (EO9-A)

As EO reconhecem que poderiam atuar muito mais, colocando em prática os conhecimentos e competências profissionais, mas, pela carência de funcionários, precisam executar tarefas burocráticas, permanecendo distantes da atenção obstétrica. Entendem que o pouco reconhecimento acontece, principalmente, por falta de oportunidades para mostrar o trabalho, sentindo-se, por vezes, "cumpridoras de tarefas", executoras das ordens médicas.

Ao mesmo tempo em que se identifica a queixa, por parte das EO, quanto a um "poder medicalizado no hospital", a literatura reconhece o exercício de múltiplos poderes, caracterizando um jogo de relações entre os diversos profissionais que atuam nesse cenário. Como o médico depende da enfermeira, tanto as enfermeiras como os médicos exercem o poder. Portanto, não podemos, segundo Borenstein, ${ }^{49}$ acreditar que o poder é hegemonicamente médico: a EO também contribui para isso, adotando uma posição de subserviência.

A minha posição na equipe da instituição? Eu acabo cumprindo tarefas e seguindo protocolos. (EO1-A)

Na visão dos outros, você é aquela que está fazendo, sei lá controlando o foco para que não aconteça nada, enquanto ele não está no hospital. (EO2-B)

Claro que nós temos exceções. Tem equipes que têm a sua conduta e que é aquilo, e a gente acaba trabalhando como um robô mesmo. (...) Tem momentos que é assim: a equipe chega aqui e você é só mais uma complementação e a equipe é estrela e ninguém toca. Aí, sim, eu posso te falar que eu estou fazendo apenas a função de um auxiliar, de uma técnica, não estou fazendo a minha função enquanto obstetriz. (EO6-A)

As EO reconhecem que existem médicos que conhecem e confiam no seu trabalho, que compreendem que a EO é uma profissional importante na equipe, como uma colaboradora na assistência às mulheres. Porém, percebem que alguns médicos desconhecem as suas atribuições e não confiam suas clientes aos seus cuidados. Para 
esses médicos, a EO é apenas uma integrante da equipe que poderia muito bem ser outro profissional, com uma auxiliar de enfermagem, por exemplo.

Acho que tem algumas equipes que não deixam você atuar como profissional. Tomar uma atitude [contrária a minha] na frente da paciente pode ser um complicador, mas é relativamente raro. Geralmente, há um respeito, porque a maioria das equipes já me conhece, existe confiança. (EO4-C)

Não é todo mundo que está a fim de trabalho de parto, é mais simples chegar e operar, isso pra mim é muito claro, é tão clara essa coisa da indicação. (EO6-A)

É possível perceber, pelos discursos, que há uma tentativa, por parte de algumas instituições, de instaurar uma política interna de humanização do parto. Algumas grandes maternidades privadas da cidade de São Paulo criaram salas ou "suítes" de parto normal, onde se encontram recursos tecnológicos para assistir a partos normais e fórceps. $\mathrm{O}$ ambiente é aconchegante, no banheiro há chuveiro e uma banheira de hidromassagem que pode ser utilizada para promover o conforto e o alívio da dor das contrações no trabalho de parto. Essas atitudes demonstram que houve um relativo interesse nas mudanças das práticas obstétricas no setor privado, provavelmente em decorrências das políticas de saúde, quanto à importância da humanização do parto. ${ }^{29}$ No entanto, nesses mesmos hospitais, há uma restrição da autonomia da EO, principalmente devida à atitudes das equipes médicas, e o numero de partos operatórios é elevado. O incentivo para a humanização do parto, que está em vigor há pelo menos dez anos, foi também criado para reduzir ou prevenir as cesáreas eletivas, porém o quadro de funcionários e EO nas instituições permaneceu o mesmo, quando deveria ter aumentado para poder oferecer uma assistência humanizada e de qualidade. Provavelmente, esta situação também contribui para os profissionais médicos que atendem suas clientes particulares não acreditem nesta alternativa e por isso, apesar do empenho das políticas públicas de saúde, bem como da direção de algumas instituições privadas, não tem havido redução nos índices de cesáreas eletivas nas maternidades do setor privado. A humanização da assistência ao parto será possível nas instituições privadas quando mudanças políticas e culturais acontecerem, inclusive na sociedade em geral, mas, principalmente, quando os 
profissionais de saúde, administradores das instituições e gestantes, assimilarem esses conceitos.

A EO tem respaldo legal para desempenhar as suas funções com autonomia, sem a necessidade da validação de um outro profissional, como um médico, quando se trata de uma gestação de baixo risco, que evolui para o parto normal. A Portaria MS/GM n. 2.815/98 reconhece a assistência prestada por essa categoria profissional, no contexto da humanização do parto. ${ }^{29}$ A ANS, através da Resolução Normativa n. 167, de 9 de janeiro de 2007, ampliou a cobertura de planos de saúde a partir de abril de 2008, possibilitando às beneficiárias ter o parto assistido por EO. ${ }^{50}$

Além dessa regulamentação, a ANS iniciou um movimento em favor do parto normal, com a finalidade de reduzir o número de cesáreas desnecessárias no setor suplementar. Encaminhou às beneficiárias de planos de saúde um informativo sobre os riscos para a mãe e o bebê em cesáreas eletivas realizadas antes de 38 semanas de gestação e sobre a importância da humanização do nascimento. Reforça, ainda, que a literatura médica associa a participação da EO e a presença do acompanhante à redução do número de cesarianas. Através desse documento, quer estimular a discussão entre as mulheres para que "ousem reivindicar o direito" de dar à luz por um parto normal com segurança. ${ }^{51}$

Posso estar sendo injusta, não sei, mas você não é vista como uma pessoa necessária, capaz e que tem competência, que tem conhecimento e sabe o que está fazendo. Sabe, para os médicos sou só mais uma auxiliar de enfermagem [risos], sinceramente, para ligar o cardiotoco, ou para ficar lá enquanto ele não pode estar. (EO2-B)

As EO sentem-se à vontade como líderes da equipe de enfermagem e são respeitadas pelas auxiliares, que reconhecem seus conhecimentos. Dentro de cada equipe, há confiança e a distribuição das tarefas acontece em harmonia. O relacionamento é mais difícil entre as equipes de outros setores.

A minha equipe [de enfermagem na maternidade] é legal, eu sinto que a minha função é de compartilhar. Temos um perfil parecido, há um respeito, sou líder sim. O reconhecimento é pouco das outras equipes do berçário ou do outro andar ou das equipes dos médicos. (EO1-A) 
Bom, eu me sinto bastante à vontade. Tem muitas coisas que eu faço. Lidero esta equipe de enfermagem e auxiliares. Cada vez mais, eu percebo que vou criando um vínculo maior de profissionalismo, de liberdade para trabalhar tranqüilo. É o dia-a-dia que me deu essa colocação, para eu estar bem mais à vontade para conversar, trabalhar, para discutir um assunto ou qualquer outra coisa. (EO10-E)

\subsubsection{Composição e coordenação da equipe de assistência ao parto}

As respostas à pergunta sobre a composição da equipe foram unânimes. Todas as EO concordaram que a equipe deve ser composta por técnicos de enfermagem, EO e médicos obstetras, neonatologista e anestesistas, principalmente por se tratar de instituições privadas, que têm uma proposta de atendimento de alta qualidade.

Eu acho que é a enfermeira, a enfermeira obstétrica, um auxiliar, técnico de enfermagem, um pediatra, óbvio, e um obstetra na retaguarda. (EO2-B)

Eu acho que uma equipe completa mesmo, uma equipe multiprofissional. Acho que tem que ter todos os profissionais, para o que der e vier. (EO6-A)

A técnica de enfermagem, a enfermeira, o obstetra, se tiver, o assistente, o anestesista e o neonatologista. (EO9-A)

$O$ médico obstetra, a enfermeira obstetra, um auxiliar de enfermagem, neonatologista, anestesista. Acho que é isso. (EO15-I)

Em uma entrevista, houve a menção à presença de uma enfermeira neonatal, quando ocorre o nascimento de um bebê com problemas sérios, alegando que as EO não têm treinamento suficiente para atuar nestas situações.

Um obstetra, uma enfermeira obstétrica. Uma coisa que a gente anda discutindo muito: a presença de uma enfermeira neonatal na recepção do recém-nascido, junto com a pediatra. (EO8-D) 
Houve a observação de que as auxiliares de enfermagem atuantes no centro obstétrico deveriam ter um treinamento teórico e prático específico, para realizar um atendimento com melhor qualidade. A presença de doulas ou familiares que tenham orientação também foi citada, pois pode ajudar a enfermagem no acompanhamento do trabalho de parto, porque oferecem à parturiente conforto, companhia e segurança.

A auxiliar de enfermagem deveria ter um treinamento específico. Muitas coisas acabam fazendo sem saber o porquê que estão fazendo; aprendem com o dia-a-dia $e$ acabam fazendo as coisas de maneira mecânica, sem saber o porquê, e fica dificil trabalhar assim. (EO10-E)

O obstetra, a enfermeira obstétrica, um técnico ou auxiliar de enfermagem para ajudar, além do anestesista, neonatologista responsável pelas admissões, pela UTI infantil e neonatal e berçário. (EO12-F)

A resposta à questão de quem deveria coordenar a assistência ao parto foi diversificada. Algumas EO entenderam a coordenação da equipe de assistência ao parto como sendo o gerenciamento do centro obstétrico, enquanto outras compreenderam a questão como a coordenação da assistência à parturiente. Segundo algumas respostas, o centro obstétrico deve ser coordenado pela EO, porque ela conhece o funcionamento da instituição e tem uma "visão do todo". Ela conhece os funcionários, suas características, os médicos e as rotinas dos setores de trabalho.

A enfermeira obstetra, claro! A gente planeja tudo desde o começo. Então, tem que ser a enfermeira obstétrica. (EO5-A)

A enfermeira, [risos] porque, quer queira quer não, a gente sabe o que está acontecendo todo tempo, no dia-a-dia. A enfermeira sempre sabe, o médico tem parto para fazer, consultas para atender, ele está em outro setor não dá para coordenar. E, além disso, ele é plantonista, ele não está todos os dias. (EO10-E)

A enfermeira obstétrica, obviamente, no que se refere à assistência de enfermagem, e os médicos, no que se refere à conduta médica. Um referencial para cada profissional, direcionado a cada área. (EO11-F) 
É a enfermeira obstetra, porque conhece todos da equipe, conhece os auxiliares. Enfim, é o integrante que consegue interagir com todas as equipes, e ele tem o embasamento de administração, de liderança, que vai favorecer o atendimento. (EO15-I)

Outras EO são da opinião que o centro obstétrico pode ser coordenado em conjunto com os profissionais envolvidos. Esta poderia ser uma oportunidade para a integração e o conhecimento pessoal e profissional, facilitando o trabalho de cada um.

Acho que não é nem um nem outro. Acho que o grupo tem que entrar em um consenso e tocar as coisas junto. (EO6-A)

Com certeza, alguém da enfermagem deveria participar $e$ opinar, porque eles conhecem o lado deles, o que fazer. A enfermagem consegue reconhecer melhor o que precisa, as falhas, a prática. Eu acho que a enfermeira, com certeza. Não só ir a reuniões e participar e opinar, mas ela ter o poder, tanto quanto o médico obstetra, e decidir junto com o médico obstetra. E a mesma coisa com o médico neonatologista e a enfermeira neonatal, porque é uma continuidade. Então, eu acho que deveria ser os quatro juntos. (EO8-D)

O médico, segundo algumas respostas, tem uma relação de confiança com a cliente, porque fez todo o acompanhamento do pré-natal na sua clínica particular, o que justifica a coordenação de todos os procedimentos. A EO também tem conhecimento e formação técnica para assumir a responsabilidade pela condução da assistência ao parto, mas, por não ser referência para a mulher, o vínculo de confiança dificilmente acontece.

A enfermeira tem condições de coordenar o processo e tem como identificar a necessidade do médico estar presente a partir do momento que ela determinar ou não. Eu não acho que ele tem que chegar na frente. (EO7-D)

Coordenar na assistência à paciente? Ah, eu acho que o obstetra da paciente, como já a conhece a paciente mais do que todo mundo, porque a obstetriz, a funcionária está conhecendo na hora. (EO9-A) 


\subsubsection{Reflexões sobre a atuação da enfermeira obstétrica nas instituições de saúde privadas}

Ao final do trabalho, cabe fazer um balanço, levando em consideração algumas questões ligadas às atribuições da EO nas instituições privadas no município de São Paulo. Ao longo da pesquisa, foi possível identificar que há poucas condições favoráveis para a EO atuar com autonomia e as barreiras para a autonomia são claramente reconhecidas.

A OMS e a ICM reconhecem que os cuidados prestados às parturientes pelas EO, além de humanizar o nascimento, estimulam a redução das altas taxas de cesarianas desnecessárias e apontam que a EO é o profissional mais indicado para atender os partos de baixo risco. OMS e, recentemente, a ANS também assegura que as EO têm total respaldo legal para desempenhar suas funções. Os movimentos e organizações da sociedade civil têm auxiliado a enfermagem obstétrica a dar passos importantes para o reconhecimento legal e valorização da sua contribuição no âmbito da saúde materna.

As EO reconhecem as suas competências, mas têm dificuldades para ocupar o seu lugar dentro da equipe obstétrica nas instituições privadas. A pouca autonomia da EO para desempenhar a suas atividades acontece não por falta de atendimento aos critérios da ICM, como competências e conhecimentos, mas principalmente, por falta de reconhecimento dos médicos quanto às suas atribuições e pelo pequeno suporte por parte da gerência de enfermagem.

Para os médicos, que insistem em recomendar a cesariana como melhor alternativa para o nascimento de uma criança, parece que o parto normal é um retrocesso às condições sujas e danosas para o binômio da era pré-tecnológica ${ }^{14}$ e a cesárea é um recurso benéfico, independentemente da indicação clínica. $\mathrm{O}$ discurso sedutor de que a cesariana é uma alternativa segura, programável, indolor e rápida ainda é bem aceito por muitas mulheres, que acreditam ser melhor entregar a tarefa de parir a um médico que assumir para si o processo de dar à luz.

As EO têm muito a contribuir, atuando como geradoras da transformação da assistência obstétrica, tornando-a menos intervencionista e mais humanizada. Elas possuem o respaldo legal, competência técnica e sensibilidade para se relacionar com 
as mulheres e seus familiares. Porém, precisam se fortalecer como um grupo profissional perante a sociedade, as instituições e os médicos, para reverter esse quadro, no sentido de atenderem as parturientes com mais autonomia e em cooperação com os médicos. É possível notar que a dificuldade em consolidar a profissão está ancorada, em particular, na falta de autonomia e de relações de cooperação com outros profissionais da área da saúde.

Quando trabalham em instituições de saúde privadas, as EO têm suas atividades tolhidas e mal compreendidas, os médicos decidem as condutas sem a sua participação. Há diferenças na maneira como a EO exerce as suas atividades, conforme o tipo de instituição em que trabalha, e isso está diretamente relacionado à autonomia, à liberdade de atuar e o trabalho colaborativo com os médicos.

O paradigma de atenção às mulheres nas instituições privadas não é compartilhado entre os dois profissionais - EO e médico obstetra. Existe um conflito permanente que dificulta o trabalho colaborativo. $O$ modelo de assistência à parturiente nas instituições privadas é desajustado das políticas oficiais de saúde. As atividades e intervenções médicas são consideradas mais importantes que os cuidados de enfermagem à mulher, principalmente porque a maioria dos partos é cirúrgico. A administração das instituições privadas sustenta a hierarquia médica, dando a eles, médicos, respaldo para trabalharem conforme os seus conhecimentos, adquiridos na sua formação, privilegiando condutas que nem sempre estão de acordo à natureza do processo de parto. A porcentagem de partos normais nessas instituições é muito pequena, poucas mulheres entram em trabalho de parto e, quando isso acontece, é comum a indicação da cesariana sem motivo ou indicação clínica.

\subsection{Considerações finais}

Avanços importantes nas políticas de saúde aconteceram durante a última década, no sentido de legitimizar e legalizar as atribuições das EO. As atribuições das EO são reconhecidas pelo MS e, a partir de 2008, as prestadoras de seguros de saúde e planos de saúde também passaram a reconhecer e oferecer cobertura à assistência ao parto realizada pela EO. Os movimentos da sociedade, com a presença 
de profissionais da área da saúde e pessoas leigas, mulheres que se frustraram com a condução de seus partos, também cooperam para o reconhecimento da importância da EO na assistência ao parto e pós-parto. Além disso, os investimentos do MS no financiamento de novos cursos de especialização em enfermagem obstétrica para a capacitação de novos profissionais vêm contribuindo e, provavelmente, influenciarão o atual modelo da assistência ao parto. Esses movimentos prestigiam e induzem mudanças no paradigma da assistência ao parto, que tiveram início nas instituições públicas na década de 1990 e lentamente estão atingindo também as instituições privadas, porém, com forte resistência da categoria médica.

O modelo de atuação da EO nas instituições privadas ainda é muito tradicional e funcionalista. A equipe de enfermagem está ancorada na hierarquização, e ainda adota uma postura de subordinação em relação aos médicos. Apesar de movimentos em favor do reconhecimento das atribuições da EO, há a necessidade de que os profissionais desta área se organizem melhor para consolidar a sua presença na equipe de assistência ao parto e afirmar seu papel, enquanto agentes transformadores dos indicadores da qualidade da assistência ao parto e do elevado índice de partos cesarias, favorecendo o parto normal.

Se as EO que trabalham nas instituições privadas tivessem atribuições mais direcionadas para a atenção à mulher na assistência ao parto e pós-parto, a minha presença no acompanhamento das mulheres no trabalho de parto e parto não seria necessária. Porém, as minhas atividades complementam com as atribuições das EO, que são em um número reduzido nos plantões, e não dispõem de tempo para atender de maneira mais próxima as necessidades das mulheres em trabalho de parto.

Para a realização desse trabalho me deparei com algumas dificuldades em particular ao fazer o contato com a chefia ou gerência de enfermagem das instituições incluídas no universo do estudo. A dificuldade de resposta à solicitação de participação no estudo limitou o número de instituições contempladas. No entanto, ao abordar pessoalmente as EO quanto à temática do estudo, todas concordaram em participar das entrevistas.

Através do contato com as EO ao longo deste trabalho, me aproximei mais do complexo universo de seu trabalho, compreendendo melhor a sua percepção quanto às suas atribuições, reconhecimento e relacionamento profissional, além de sua vivência no desempenho das atividades. Foi possível observar que a assistência das 
EO às mulheres no parto é superficial e distante, visto que a maioria dos partos é cirúrgico e, quando há mulheres em trabalho de parto, principalmente nas instituições de "corpo clínico aberto", o médico está presente, assumindo integralmente a assistência e a condução do trabalho de parto. Esta realidade prioriza e valoriza principalmente o relacionamento da EO com o médico, ao invés do contato com a mulher. As EO atuam no sentido de suprir as necessidades dos médicos para que eles possam assistir as mulheres. O trabalho da EO nas instituições de saúde privadas se configura mais como "trabalho meio" do que, propriamente, "trabalho fim". É possível perceber que a assistência obstétrica nestas instituições baseia-se em uma relação assimétrica, impessoal, com rotinas e intervenções, com pouco respeito aos direitos e opiniões das mulheres, dificultando que elas sejam ativas no seu próprio processo de parto e, ao mesmo tempo, "desreponsabilizando-as" do poder de escolha.

O trabalho das EO está a caminho para se consolidar novamente perante a sociedade como um todo, como o profissional mais adequado para a assistência ao parto normal e de baixo risco. Porém. nas instituições privadas a EO ainda encontra muitos desafios para superar e resistências, principalmente no que se refere ao reconhecimento dos médicos e das mulheres gestantes em geral, quanto as suas atribuições.

Este trabalho merece uma continuidade no sentido de ouvir dos médicos obstetras e das chefias de enfermagem, o modo de ver e a opinião quanto aos paradigmas da atenção e assistência ao parto e pós-parto nas instituições privadas. Acredito que seria interessante conhecer o que pensam os médicos a esse respeito, principalmente porque algumas questões poderiam ser respondidas facilitando a compreensão do relacionamento entre médicos, enfermeiras obstétricas e gestantes, e qual a percepção que possuem sobre a atenção obstétrica. Se as atribuições das EO são reconhecidas até por organismos internacionais, por que ainda há resistência em desenvolver um trabalho colaborativo? Se houvesse colaboração entre as atribuições do médico e da EO, as mulheres poderiam ser ouvidas e respeitadas quanto aos seus desejos da via de parto contribuindo para a redução dos altos índices de cesarianas desnecessárias? Este reconhecimento poderia melhorar a qualidade do relacionamento profissional e, em conseqüência, da assistência às mulheres. 


\section{REFERÊNCIAS BIBLIOGRÁFICAS}

1. Jorge DR. Evolução da legislação federal do ensino e do exercício profissional da obstetriz (parteira) no Brasil. [tese]. Rio de Janeiro: Escola de Enfermagem Anna Nery - Universidade Federal do Rio de Janeiro; 1975.

2. Mott ML. A parteira ignorante: um erro de diagnóstico médico? Revista Estudos Feministas. 1999;(1/2):25-36.

3. Vann MK. Professional autonomy for midwifes. An essential component of collaborative practice. J Nurse Midwifery. 1998;43(1):41-5.

4. Mott ML. As parteiras e a assistência ao parto em São Paulo nas primeiras décadas do século XX. Revista do Instituto Histórico Geográfico Brasileiro. 2002;415:67-84.

5. Osava RH. Assistência ao parto no Brasil: o lugar do não-médico. [tese]. São Paulo: Faculdade de Saúde Pública da Universidade de São Paulo; 1997.

6. Kitzinger S. The midwife challenge. London: Pandora; 1988.

7. Oliveira SMJV, Gonzalez Riesco ML, Rosas Miya CF, Vidotto P. Tipo de parto: expectativas das mulheres. [Childbirth types: women's expectations]. Rev Latinoam Enferm. 2002;10(5):667-74.

8. Mott ML. Assistência ao parto: do domicilio ao hospital (1830-1960). Revista Projeto História. 2002;25:197-219.

9. Kitzinger S. The politics of birth. Edinburgh: Elsevier; 2005.

10. Zagonel IPS. Exercício do poder diante da complexidade das relações no espaço médico-hospitalar e de enfermagem. [Power exercise facing the complexity of relations in medical-hospital and nursing]. Cogitare Enferm. 1996;1(2):75-80.

11. Riesco MLG. Que parteira é essa? [tese]. São Paulo: Escola de Enfermagem da Universidade de São Paulo; 1999. 
12. Bonadio IC, Andreoni S, Gonzalez Riesco ML, Ortiz ACLV. Levantamento do número de enfermeiros obstetras formados nos últimos 20 anos pelas Escolas de Enfermagem do Brasil. Nursing (Sao Paulo). 1999;2(8):25-9.

13. Febrasgo. Aprovados no TEGO em 2007. Relação de aprovados no TEGO, Título de Especialista em Ginecologia e Obstetrícia 2007. Disponível em: http://www.febrasgo.org.br/AprovadosTego2007/tabid/117/Default.aspx. Acessado em 2008 (10 abr).

14. Diniz CSG. Entre a técnica e os direitos humanos: possibilidades e limites da humanização da assistência ao parto. [Between technique and human rights: possibilities and constraints to the humanization care in childbirth]. [tese]. São Paulo: Faculdade de Medicina da Universidade de São Paulo; 2001

15. Hotimsky SN. A formação em obstetrícia: competência e cuidado na atenção ao parto. [tese]. São Paulo: Faculdade de Medicina da Universidade de São Paulo; 2007.

16. Stapleton SR. Team building. Making collaborative practice work. J Nurse Midwifery. 1998;43(1):12-8.

17. Angulo-Tuesta A, Giffin K, Gama Ade S, d'Orsi E, Barbosa GP. Saberes e práticas de enfermeiros e obstetras: cooperação e conflito na assistência ao parto. [Cooperation and conflict in childbirth care: representations and practices of nurses and obstetricians]. Cad Saude Publica. 2003;19(5):1425-36.

18. Payne PA, King VJ. A model of nurse-midwife and family physician collaborative care in a combined academic and community setting. J Nurse Midwifery. 1998;43(1):19-26.

19. Brasil VV, Alencar CCP, Mucci I. Refletindo sobre a formação e desempenho do docente de enfermagem. [Thinking about the competence and performance of the nursing faculty]. Cogitare Enferm. 1996;1(2):81-5.

20. Fleming VE. Autonomous or automatons? An exploration through history of the concept of autonomy in midwifery in Scotland and New Zealand. Nurs Ethics. 1998;5(1):43-51. 
21. Hunter B. Conflicting ideologies as a source of emotion work in midwifery. Midwifery. 2004;20(3):261-72.

22. Brasil. Ministério da Saúde. Indicadores de cobertura. Proporção de partos hospitalares. Disponível em: http://tabnet.datasus.gov.br/cgi/deftohtm.exe?idb2006/f07.def. Acessado em 2008 (18 mar).

23. Agência Nacional de Saúde Suplementar. Proporção de parto cesáreo. Disponível em: http://www.ans.gov.br/portal/upload/informacoesss/AS1fase.pdf. Acessado em 2008 (18 mar).

24. Brasil. Ministério da Justiça. Agência Nacional de Saúde Suplementar - ANS. Lei $\mathrm{n}^{\mathrm{o}}$ 9.961, de 28 de janeiro de 2000. Publicada no Diário Oficial da União de 29.01.2000. Disponível em: http://www.cade.gov.br/legislacao/ag_ans.asp. Acessado 2008.

25. Agência Nacional de Saúde Suplementar. Caderno de informação da saúde suplementar beneficiários, operadoras e planos. Disponível em: http://www.ans.gov.br/portal/upload/informacoesss/caderno_informaca_09_2007.pdf Acessado em 2008 (18 mar).

26. Brasil. Ministério da Saúde. Secretaria de Atenção à Saúde. Datasus. Indicadores. Leitos. Disponível em: http://cnes.datasus.gov.br/Mod_Ind_Tipo_Leito.asp. Acessado em 2008 (18 abr).

27. Carr M, Riesco ML. Rekindling of nurse-midwifery in Brazil: public policy and childbirth trends. J Midwifery Womens Health. 2007;52(4):406-11.

28. Rehuna. Missão. Disponível em: http://www.rehuna.org.br. Acessado em 2008 (19 mar).

29. Brasil. Ministério da Saúde. Secretaria de Políticos de Saúde. Área Técnica de Saúde da Mulher. Parto, aborto e puerpério: assistência humanizada à mulher. Ministério da Saúde, Secretaria de Políticas de Saúde, Área Técnica da Mulher. Brasília: Ministério da Saúde; 2001. Disponível em: http://bvsms.saude.gov.br/bvs/publicacoes/cd04_13.pdf. Acessado em 2008 (02 abr). 
30. Perroca MG, Soler ZASG. Desempenho profissional de enfermeiras de um hospital de ensino: influencia da cultura organizacional. [Nurses' performances in a school hospital: the organizational culture influence]. Acta Paul Enferm. 1998;11(3):16-23.

31. Brasil. Decreto $\mathrm{n}^{\mathrm{o}}$ 94.406, de 08 de junho de 1987. Publicado no DOU de 09.06.87, seção I - fls. 8.853 a 8.855. Regulamenta a Lei $\mathrm{n}^{\mathrm{o}} 7.498$, de 25 de junho de 1986, que dispõe sobre o exercício da Enfermagem, e dá outras providências. Brasília, 08 de junho de 1987. Disponível em: http://www.portalcorenrs.gov.br/web/legislacao/decretos/d94406.htm. Acessado em 2008 (10 abr).

32. Organização Mundial de Saúde. Maternidade segura. Assistência ao parto normal: um guia prático. Genebra: Organização Mundial de Saúde: 1996.

33. Enkin M, Keirse MJNC, Neilson J, Crowther C, Duley L, Hodnett E, et al. Guia para atenção efetiva na gravidez e no parto. $3^{\underline{a}}$ ed. Rio de Janeiro: Guanabara Koogan; 2005.

34. Hodnett ED. Pain and women's satisfaction with the experience of childbirth: a systematic review. Am J Obstet Gynecol. 2002;186(5 Suppl Nature):S160-72.

35. Fullerton JT, Thompson JB. Examining the evidence for The International Confederation of Midwives' essential competencies for midwifery practice. Midwifery. 2005;21(1):2-13.

36. Matthews A, Anne Scott P, Gallagher P, Corbally MA. An exploratory study of the conditions important in the facilitating the empowerment of midwives. Midwifery. 2006;22(2):181-91.

37. Ferreira ABH. Dicionário Aurélio da Língua Portuguesa. Rio de Janeiro: Nova Fronteira; 1988.

38. Pollard K. Searching for autonomy. Midwifery. 2003;19(2):113-24.

39. McKay S. The route to true autonomous practice for midwives. Nurs Times. 1997;93(46):61-2.

40. Perrenoud P. Construir as competências desde a escola. Porto Alegre: Artmed; 1999. 
41. Faustino RLH, Moraes MJB, Oliveira MAC, Egry EY. Caminhos da formação de enfermagem: continuidade ou ruptura? [Paths to nursing education: continuity or rupture?] Rev Bras Enferm. 2003;56(4):343-47.

42. Dotto LMG. Atenção qualificada ao parto: a realidade da assistência de enfermagem em Rio Branco (AC). [tese]. Ribeirão Preto: Escola de Enfermagem Ribeirão Preto da Universidade de São Paulo; 2006.

43. Kramer M, Schmalenberg CE. Magnet hospital staff nurses describe clinical autonomy. Nurs Outlook. 2003;51(1):13-9.

44. Keleher KC. Collaborative practice. Characteristics, barriers, benefits, and implications for midwifery. J Nurse Midwifery. 1998;43(1):8-11.

45. Jackson DJ, Lang JM, Swartz WH, Ganiats TG, Fullerton J, Ecker J, et al. Outcomes, safety, and resource utilization in a collaborative care birth center program compared with traditional physician-based perinatal care. Am J Public Health. 2003;93(6):999-1006.

46. Cardoso V. A cooperação entre o médico e enfermeira na equipe interdisciplinar. [Physician - nurse cooperation in the interdisciplinary team]. Texto \& Contexto Enferm. 1997;6(2):162-7.

47. Minayo MCS. O desfio do conhecimento: pesquisa qualitativa em saúde. $8^{\mathrm{a}}$ ed. São Paulo: Hucitex; 2004.

48. Brasil. Ministério da Saúde. Secretaria de Atenção à Saúde. Datasus. Indicadores. Leitos. Tipo Leito - Obstetrícia Cirúrgica. Disponível em: http://cnes.datasus.gov.br/Mod_Ind_Leitos_Listar.asp?VCod_Leito=10\&VTipo_Leit $\mathrm{o}=4 \&$ VListar $=1 \&$ VEstado=35\&VMun=355030. Acessado em 2007 (20 jan).

49. Borenstein MS. Poder da enfermagem no espaço hospitalar. [Power of nursing in the hospital space]. Texto \& Contexto Enferm. 2000;9(3):42-53.

50. Brasil. Ministério da Saúde. Agência Nacional de Saúde Suplementar. ANS amplia cobertura obrigatória de planos de saúde a partir de abril. Disponível em: http://www.ans.gov.br/portalv4/site/noticias/noticia_25163.asp?secao=Home. Acessado em 2008 (02 abr). 
51. Brasil. Ministério da Saúde. Agência Nacional de Saúde Suplementar. Regulamentações normativas. Resolução Normativa - RN no 167 , de 9 de Janeiro de 2007. Atualiza o Rol de Procedimentos e Eventos em Saúde, que constitui a referência básica para cobertura assistencial nos planos privados de assistência à saúde, contratados a partir de $1^{0}$ de janeiro de 1999, fixa as diretrizes de Atenção à Saúde e dá outras providências. Disponível em: http://www.ans.gov.br/portal/site/legislacao/legislacao_integra.asp?id=1084\&id_origi nal $=0$. Acessado em 2008 (02 abr). 


\section{ANEXOA}

\section{$\underline{\text { Roteiro para entrevista }}$}

1. Quando e onde nasceu?

2. Onde e em que ano se formou?

3. Há quanto tempo está formada como Enfermeira?

4. Há quanto tempo está formada como Enfermeira obstétrica?

5. Descreva sua atividade cotidiana na assistência a mulher no trabalho de parto e parto, considerando aspectos que representam o trabalho colaborativo entre enfermeiras obstétricas e médicos da equipe obstétrica, a autonomia profissional da enfermeira obstétrica e a restrição desta autonomia.

6. Quem você considera que deve compor uma equipe de assistência ao parto?

7. Você acha que deve coordenar uma equipe de assistência ao parto?

8. Você entende que a sua atuação profissional é exercida com autonomia?

9. Você entende que, na sua atuação, acontece o trabalho colaborativo?

10. O que facilita o seu desempenho profissional com autonomia?

11. Quais as barreiras para o trabalho com autonomia?

12. O que facilita o trabalho colaborativo?

13. Quais as barreiras para o trabalho colaborativo?

14. Qual a sua percepção da sua posição profissional? 


\section{UNIVERSIDADE DE SÃO PAULO ESCOLA DE ENFERMAGEM}

Av. Dr. Enéas de Carvalho Aguiar, 419 - CEP 05403-000

Tien Fone.: 3066-7548 - Fax.: 280-8213

C.P. 41633 - CEP 05422-970 - e-mail.: ee@edu.usp.br

São Paulo, 21 de junho de 2000.

$\mathrm{Ilm}^{\mathrm{a}} \mathrm{Sr}^{\mathrm{a}}$

PROF $^{\text {a }}$ DR $^{\text {a }}$ MARIA LUIZA GONZALEZ RIESCO

Ref.: Processo $\mathrm{n}^{\circ}$ 56/2000

Em atenção à solicitação referente à análise do projeto

"LIMITES E DELIMITAÇÕES DA PRÁTICA: A AUTONOMIA PROFISSIONAL DA ENFERMEIRA OBSTÉTRICA", informamos que o mesmo foi considerado aprovado pelo Comitê de Ética em Pesquisa da Escola de Enfermagem da Universidade de São Paulo (CEP/EEUSP).

Analisado sob o aspecto ético-legal, atende às exigências da Resolução nº 196/96 do Conselho Nacional de Saúde.

Esclarecemos que após o término da pesquisa, os resultados obtidos deverão ser encaminhados ao CEP/EEUSP, para serem anexados ao processo.

Atenciosamente,

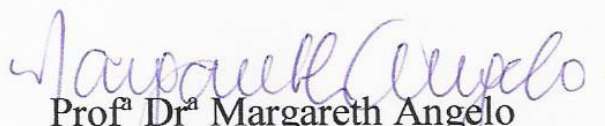

Prof ${ }^{\mathrm{a}} \mathrm{Dr}^{\mathrm{a}}$ Margareth Angelo

Coordenadora do Comitê de Ética em Pesquisa

da Escola de Enfermagem da Universidade de São Paulo 


\section{ANEXO C}

\section{Termo de Consentimento Livre e Esclarecido}

Prezada Colega,

Meu nome é Doris Ammann Saad, sou enfermeira obstétrica e aluna do Curso de Mestrado da Escola de Enfermagem da Universidade de São Paulo.

Estou realizando a pesquisa "Autonomia Profissional da Enfermeira Obstétrica", sob orientação da $\operatorname{Prof}^{\mathrm{a}} \operatorname{Dr}^{\mathrm{a}}$ Maria Luiza Gonzalez Riesco e venho solicitar sua valiosa colaboração. A pesquisa tem como objetivo conhecer e analisar como a enfermeira obstétrica percebe sua inserção e atuação junto à mulher na assistência durante o trabalho de parto, parto e pós-parto e o relacionamento profissional com equipe. Neste sentido, solicito seu depoimento gravado.

Informo que será garantido seu anonimato na divulgação dos dados, sendo que os resultados serão apresentados em eventos científicos e encaminhados para publicação em periódicos da área. Saliento que sua participação é inteiramente voluntária, estando assegurado o direito de não fornecer seu depoimento e, também, de requerer sua exclusão da pesquisa em qualquer momento, durante a realização da mesma. Para qualquer esclarecimento ou solicitação posterior, forneço o número do meu telefone: (11) 4146-6061.

O projeto tem parecer favorável do Comitê de Ética da Escola de Enfermagem da Universidade de São Paulo, telefone (11) 3061-7548.

Contando com sua colaboração, antecipadamente agradeço.

São Paulo, $/ 2007$ 